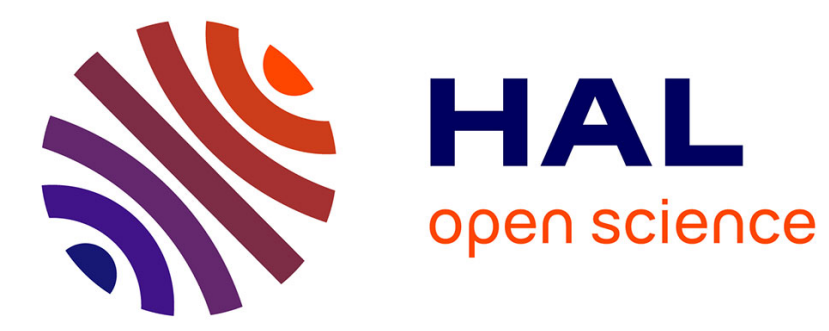

\title{
Unequal vulnerability to climate change and the transmission of adverse effects through international trade
}

Karine Constant, Marion Davin

\section{- To cite this version:}

Karine Constant, Marion Davin. Unequal vulnerability to climate change and the transmission of adverse effects through international trade. 2018. hal-01947416

\section{HAL Id: hal-01947416 \\ https://hal.umontpellier.fr/hal-01947416}

Preprint submitted on 7 Dec 2018

HAL is a multi-disciplinary open access archive for the deposit and dissemination of scientific research documents, whether they are published or not. The documents may come from teaching and research institutions in France or abroad, or from public or private research centers.
L'archive ouverte pluridisciplinaire HAL, est destinée au dépôt et à la diffusion de documents scientifiques de niveau recherche, publiés ou non, émanant des établissements d'enseignement et de recherche français ou étrangers, des laboratoires publics ou privés. 


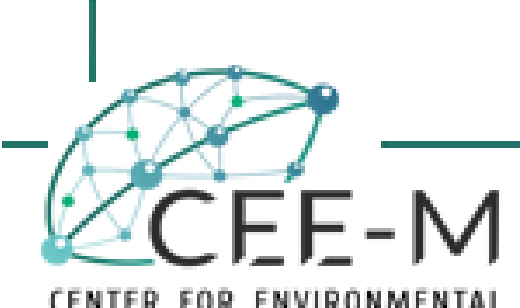

CENTER FOR ENVIRONMENTAL ECONOMICS - MONTPELLIER

\section{Unequal vulnerability to climate change and the transmission of adverse effects through international trade}

Karine Constant \& Marion Davin

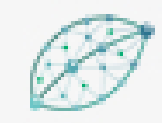

CEE-M Working Paper 2018-05 


\title{
Unequal vulnerability to climate change and the transmission of adverse effects through international trade *
}

\author{
Karine Constant ${ }^{\dagger}$ and Marion Davin ${ }^{\ddagger}$
}

February, 2018

\begin{abstract}
In this paper, we consider the unequal distribution of climate change damages in the world and we examine how the underlying costs can spread from a vulnerable to a non-vulnerable country through international trade. To focus on such indirect effects, we treat this topic in a North-South trade overlapping generations model in which the South is vulnerable to the damages entailed by global pollution while the North is not. We show that the impact of climate change in the South can be a source of welfare loss for northern consumers, in both the short and the long run. In the long run, an increase in the South's vulnerability can reduce the welfare in the North economy even in the case in which it improves its terms of trade. In the short run, the South's vulnerability can also represent a source of intergenerational inequity in the North. Therefore, we emphasize the strong economic incentives for non-vulnerable and a fortiori less-vulnerable - economies to reduce the climate change damages on - more vulnerable countries.
\end{abstract}

JEL Classification: F18; F43; O41; Q56

Keywords: International trade, Climate change, Heterogeneous damages, Overlapping generations.

${ }^{*}$ We thank participants at the conferences LAGV (2017, Aix-en-Provence), EAERE (2017, Athen), FAERE (2017, Nancy) and at the workshops on location choices and environmental economics (2017, Pau) and on growth, environment and population (2017, Nanterre) for their helpful comments. We also thank an anonymous referee from the French Association of Environmental and Resource Economists for wise suggestions. Supports from ANR GREEN-econ (ANR-16-CE03-0005) are gratefully acknowledged.

${ }^{\dagger}$ Université Paris Est, Erudite, UPEC, 61 Av. du Général de Gaulle, Mail des meche, 94010 Créteil, France. E-mail : karine.constant@u-pec.fr

${ }^{\ddagger}$ CEE-M, Univ Montpellier, CNRS, INRA, SupAgro, Montpellier, France. E-mail: marion.davin@umontpellier.fr 


\section{Introduction}

Climate change is one of the most serious environmental issues worldwide. While the substantial stock of greenhouse gases released in the atmosphere by human activities is responsible for a global climate change, it consists in return in an increase in temperature and in an increasing occurrence of extreme events according to the Intergovernmental Panel on Climate Change (IPCC, 2014). A report of the United Nations Environment Program and the World Trade Organization reveals that the consequences from climate change are expected to become more widespread but also to intensify and that "even with small increases in average temperature, the type, frequency and intensity of extreme weather - such as hurricanes, typhoons, floods, droughts, and storms - are projected to increase" (WHO-UNEP, 2009, p viii). Such a global phenomenon represents therefore an increasing threat to economic activities that will lead to substantial losses in terms of production and population well-being, as well as a serious threat to intergenerational equity, by placing an increasing burden on future generations.

An interesting peculiarity of these losses is that their intensity varies considerably across countries. A large number of studies shows the higher vulnerability of developing countries to climate change (see e.g. IPCC, 2014). The main reasons identified stem from their lower incomes, limiting their ability to adapt to weather changes, but also from geographical causes. Indeed, Stern (2006) points out that "climate change will have a disproportionately damaging impact on developing countries due, in part at least, to their location in low latitudes, the amount and variability of rainfall they receive, and the fact that they are 'already too hot' (see Mendelsohn et al., 2006)".

Some developed countries might accordingly be led to believe that the fight against climate change (i.e. mitigation) is mainly related to altruistic and fairness motives, and hence led to focus on their own adaptation. However, even if they are relatively preserved from the direct consequences of global pollution, the globalization and the resulting economic interdependence through international trade implies that damages from climate change in developing countries may also affect them. Empirically, Jones and Olken (2010) confirm that higher temperatures have no direct effect on rich countries' exports (at least for now), while they reduce significantly the growth of poor countries' exports. They conclude that rich regions may thus be indirectly affected by raising prices and reducing quantities of goods imported from poor regions. Focusing on the agricultural sector, Costinot et al. (2016) also find that the ill effects of climate change 
is damped when production adjustments caused by the evolution of comparative advantage are taken into account. The macroeconomic consequences of climate change are therefore related to its effects on trade flows, on comparative advantage across countries and, more generally, on international trade. All these elements hence stress the importance of studying if and how pollution costs could be transmitted from developing to developed countries through international trade. This is the purpose of our paper.

Overall, there is an extensive literature on trade and the environment, many of which attempts to explain the specialization of countries in green or polluting activities (see Copeland and Taylor, 2004 for a literature review). In particular, trade theory identifies the role of differences in the stringency of environmental regulation (pollution haven hypothesis), in factor endowments or in technology between countries to explain trade flows. However, so far, little attention has been given to the disparities of countries in terms of vulnerability to environmental damages while it could have significant consequences on international trade.

In this regard, two recent contributions represent notable exceptions. On one hand, using a computable general equilibrium model, Schenker (2013) shows that exogenous damages on developing countries affect the relative price of goods and in this way deteriorate the terms of trade of developed countries. He estimates that such an effect could be responsible for $16.4 \%$ of the total expected cost of climate change in the United States in 2100. On the other hand, through a static general equilibrium model, Ollivier (2016) points out that northern countries can have comparative advantage in the dirty sector, due to the lower vulnerability of their consumers to pollution that leads to a less stringent environmental regulation. Moreover, she finds that this specialization pattern benefits to the welfare of northern agents. ${ }^{1}$

Consequently, while it is clear that the higher vulnerability to climate change of developing countries may affect the national welfare of developed countries through international trade, determining whether this effect is positive or negative and identifying the mechanisms through which it occurs remain open and crucial issues, on which this paper aims at shedding some new light. To address these issues, we consider the possible changes in both the terms of trade and the comparative advantage of countries over time, therefore extending the works of Schenker (2013) and Ollivier (2016).

In addition, we go one step further by taking into account the intergenerational dimension of

\footnotetext{
${ }^{1}$ However, note that the issues addressed by Ollivier (2016) differ from ours. While we focus on the transmission of indirect effects of climate change across countries, she examines if trade increases pollution and/or welfare given the unequal vulnerability of countries to pollution.
} 
the consequences associated to the unequal vulnerability of countries to climate change. The reason is twofold. First, considering that generations overlap, agents may over- or under-accumulate capital relatively to the Pareto optimum. The potential impact of damages on the behavior of agents may thus have different economic implications according to the dynamic efficiency properties of the economy.

Second, the welfare effects of the unequal damages may also be unequally distributed across generations. Such welfare variations across generations correspond to intergenerational inequity. Since Howarth and Norgaard (1992) and John and Pecchenino (1994), authors have increasingly explored this dimension in environmental economics and emphasized that pollution may indeed lead to intergenerational inequity (see e.g. Seegmuller and Verchère, 2004, Schumacher and Zou, 2008, Varvarigos, 2011 or Constant and Davin, 2017). Given the high persistence of greenhouse gases in the atmosphere, such a key issue seems particularly important in the context of climate change.

To deal with all these dimensions, we are using a dynamic general equilibrium model with overlapping generations. We formalize two regions, North and South, representing developed and developing countries respectively. They can produce and trade two goods - a green good and a brown good whose production generates pollution emissions. The stock of pollution, which evolves over time with economic activities, is responsible for damages unequally distributed around the world. There is a risk - increasing with the pollution stock - that extreme events destroy a share of the production. In this paper, we do not examine the uncertainty associated with extreme weather but focus on the deterministic effect of pollution on economic activity. Therefore, our pollution damages can also represent the productivity loss associated with the increase in temperature (see e.g. Dell et al. , 2012 or Burke et al., 2015). In order to take into account the significant difference in terms of vulnerability between countries in a simple way, we assume that South is the only region that suffers from the direct damages due to climate change, while North is non-vulnerable.

With this dynamic model, we obtain that the lifetime welfare of northern agents evolves across time until the economy converges to its long-term state. When the South' production is altered by climate change, the usual positive trend in welfare resulting from capital accumulation is questioned for both countries. More precisely, in the South region, climate damages impact negatively the net output of firms, and hence the remuneration of production factors and capital accumulation. By making capital more scarce, pollution affects the world prices and entails a negative income effect on northern agents. When pollution gets too high, so does the extent of 
this negative effect. Therefore, we can observe that the welfare of successive northern generations declines constantly over time, characterizing intergenerational inequity as the younger generation is worse off than its parents.

Second, in the long run, we examine how an increase in the vulnerability of the South to climate change affects the stationary welfare of northern agents. We identify two channels: a terms of trade effect and a dynamic (in)efficiency effect. Both effects occur through the decrease in the world relative price of the green good driven by the increase in damages.

On one hand, movements in the world price modify the terms of trade. This generates a positive or a negative impact on the welfare in the North depending on its comparative advantage, which depends itself on the extent of the South's vulnerability. When this vulnerability is low, the North has a comparative advantage in the green sector. However, when this vulnerability is high, the relative capital abundance of the North becomes sufficiently high that it has a comparative advantage in the polluting - capital intensive - activities, despite its larger productivity in the green production. While the fall in the relative price of green to brown goods deteriorates the terms of trade in the first case, it improves it when the North is a net exporter of the polluting good. Thus, the terms of trade effect on northern agents' welfare is positive when the South's vulnerability is high, and negative otherwise.

On the other hand, the dynamic (in)efficiency effect depends on the dynamic efficiency properties of the North, i.e. if northern agents under- or over-accumulate capital with respect to the socially optimal solution. As the vulnerability of the South decreases the relative price of the green - labor intensive - good, damages entail a negative income effect on northern workers which reduces their ability to accumulate capital. Therefore, this effect is positive on welfare when the North over-accumulates capital, while otherwise it worsens under-accumulation and harms the welfare of agents.

The two effects of the South's vulnerability to climate change on northern agents' welfare can act either in same or opposite directions. In fine, we show that the North region suffers from the higher damages abroad, as long as agents' preferences for present over future consumption are sufficiently high. Unlike Schenker (2013), this is the case even if there is an improvement in the North's terms of trade.

The paper is organized as follows. In Section 2, we introduce the theoretical model. Section 3 focuses on the equilibrium in the world economy with free trade, while the welfare implications of environmental damages is examined in Section 4. Finally, we conclude and discuss the policy 
implications of our results in Section 5, while technical details are relegated to an appendix.

\section{The model}

Consider an infinite-horizon world economy comprised of finitely-lived individuals and perfectly competitive firms. Time is discrete and indexed by $t=0,1,2, \ldots, \infty$. The world economy consists of two large (industrialized) regions, North and South referred to $N$ and $S$ respectively. We assume a dynamic Ricardian framework in which the two regions differ only with respect to their total factor productivity (TFP) in each sector and their vulnerability to climate change. They are identical in terms of labor endowment, technologies and preferences.

\subsection{Production and Pollution}

In each competitive economy $i \in\{N, S\}$, there are two sectors $j \in\{b, g\}$, one representative firm by sector and each firm produces one tradable good by using capital and labor resources at each date. The two goods consist in a brown good $Y_{b, t}^{i}$ and a green good $Y_{g, t}^{i}$. For the sake of simplicity, the brown good production generates a pollution flow, while the green good production does not. The stock of labor is normalized to one and given by $L_{t}^{i}=L_{b, t}^{i}+L_{g, t}^{i}=1$, and the capital stock is given by $K_{t}^{i}=K_{b, t}^{i}+K_{g, t}^{i}$. Using these production factors, the two goods are assumed to be produced with a Cobb-Douglas technology in each region:

$$
Y_{j, t}^{i}=A_{j}^{i}\left(K_{j, t}^{i}\right)^{\alpha_{j}}\left(L_{j, t}^{i}\right)^{1-\alpha_{j}}
$$

where $0<\alpha_{j}<1$ is the distribution parameter for factors in sector $j$ and $A_{j}^{i}$ is the total factor productivity (TFP) in sector $j$. In this paper, we consider the cross-region differences in sectoral TFP $A_{j}^{i}$ as a motive for international trade, in accordance with recent empirical contributions (e.g. Fadinger and Fleiss, 2011 and Kerr, 2017). ${ }^{2}$

Regarding the pollution intensity of sectors, it is found empirically that more physical capital intensive sectors generate more pollution than those relying more heavily on labor, both in developing and developed economies, partly because of their larger consumption in terms of energy (see e.g. Cole and Elliott, 2005 ; Cole et al., 2008 ; Managi et al., 2009 and Broner et al., 2012). A recent study of Andersen (2017) concludes also that pollution emission is higher for industries that use more intensively tangible assets, such as physical capital, than intangible assets, such

\footnotetext{
${ }^{2}$ We do not consider regulation differences and hence leave aside the Pollution Haven Hypothesis issue.
} 
as human capital. We therefore assume that the brown sector is the most physical capital intensive and produces an investment good (physical capital), while the green sector produces a consumption good. ${ }^{3}$

Assumption 1. $\alpha_{b}>\alpha_{g}$.

The flow of pollution emissions in each region $i$ is a by-product of its production of the brown $\operatorname{good} Y_{b, t}$.

$$
E_{t}^{i}=\theta Y_{b, t}^{i}
$$

with $\theta>0$ an exogenous parameter, identical in each region, that controls the size of the carbon intensity.

The global stock of pollution, representing the stock of greenhouse gases (hereafter GHG, e.g. carbon dioxide, methane, nitrous oxide or ozone) in the atmosphere, increases with the emission flows of each region and partly leaves the atmosphere through a natural process in a share $0<\eta<1$ (finite lifetime of GHG).

$$
G_{t+1}=(1-\eta) G_{t}+E_{t}^{N}+E_{t}^{S}
$$

As Golosov et al. (2014) and Dietz and Stern (2015), we consider that damages due to the level of GHG reduce the aggregate output. More precisely, at each period, the stock of pollution causes a damage that destroys a part $1-\Psi^{i}\left(G_{t}\right)$ of production in each sector. We define the undamaged part of production $\Psi^{i}\left(G_{t}\right)$ as this standard functional form:

$$
\Psi^{i}\left(G_{t}\right)=\frac{1}{1+\gamma^{i} G_{t}^{2}}
$$

where $\gamma^{i}>0$ captures the vulnerability of region $i$ to global pollution. Damages are hence maximum (i.e. all production is destroyed) when $G_{t}$ tends to $+\infty\left(\Psi^{i}\left(G_{t}\right) \rightarrow 0\right)$, while they are minimum (i.e. production is not affected) when $G_{t}$ tends to $0\left(\Psi^{i}\left(G_{t}\right) \rightarrow 1\right)$.

This paper takes into account the fact that developing countries are much more vulnerable to climate change than developed countries (see e.g. Mendelsohn et al., 2006 ; Stern, 2006 or IPCC, 2014). To represent this significant difference in terms of vulnerability in a simple way and to focus on how climate change may affect the North through trade, we assume that the South is

\footnotetext{
${ }^{3}$ We could consider the case where the brown sector produces a composite good used to save and to consume. However, it would make the analysis much more complex without changing the results (as long as the elasticity of substitution between brown and green consumption goods is one).
} 
the only region that suffers from climate change, and thus that there is no direct damage in the North (i.e. $\gamma^{N}=0$ ). Then, in the remainder of the paper, we assume the following. ${ }^{4}$

Assumption 2. $\gamma^{N}=0$ and $\gamma^{S}=\gamma>0$

In region $i$, the representative firm of each sector $j$ chooses inputs by maximizing its profit $\Pi_{j}^{i}$ at each period $t$. Assuming perfect factor mobility between sectors, the latter are given by the following equation.

$$
\Pi_{j}^{i}=p_{j, t}^{i} \Psi^{i}\left(G_{t}\right) Y_{j, t}^{i}-R_{t}^{i} K_{j, t}^{i}-w_{t}^{i} L_{j, t}^{i}
$$

where $p_{j, t}^{i}$ denotes the price of good $j$ in region $i$, and $w_{t}^{i}$ and $R_{t}^{i}$ denote the wage and the rental rate of physical capital in region $i$ respectively. With competitive factor markets, workers and capital owners are paid their marginal value products by the industry in which they are employed. With $k_{j, t}^{i} \equiv K_{j, t}^{i} / L_{j, t}^{i}$ representing the physical capital intensity of sector $j$, we derive the following factor prices.

$$
R_{t}^{i}=\Psi^{i}\left(G_{t}\right) A_{j}^{i} \alpha_{j}\left(k_{j, t}^{i}\right)^{\alpha_{j}-1} p_{j, t}^{i} \quad ; \quad w_{t}^{i}=\Psi^{i}\left(G_{t}\right) A_{j}^{i}\left(1-\alpha_{j}\right)\left(k_{j, t}^{i}\right)^{\alpha_{j}} p_{j, t}^{i}
$$

We let the brown good be the numeraire and normalize its price to 1 such that $p_{g, t}^{i}$ is the price of the green good as well as the relative price of green to brown goods. Solving the first-order conditions (6) with perfect mobility of factors between sectors, we obtain the optimal demand function for physical capital intensity used in each sector.

$$
\frac{k_{g, t}^{i}}{k_{b, t}^{i}}=\frac{\left(1-\alpha_{b}\right) \alpha_{g}}{\left(1-\alpha_{g}\right) \alpha_{b}}
$$

Then, we deduce from the two previous equations that the relative price of the green good $p_{g, t}^{i}$ is:

$$
p_{g, t}^{i}=\left(\frac{A_{b}^{i}}{A_{g}^{i}}\right)\left(\frac{k_{b, t}^{i}}{\Lambda_{b}}\right)^{\alpha_{b}-\alpha_{g}}
$$

with

$$
\Lambda_{b}=\left(\frac{\alpha_{g}}{\alpha_{b}}\right)^{\frac{\alpha_{g}}{\alpha_{b}-\alpha_{g}}}\left(\frac{1-\alpha_{g}}{1-\alpha_{b}}\right)^{\frac{1-\alpha_{g}}{\alpha_{b}-\alpha_{g}}}
$$

\footnotetext{
${ }^{4}$ We could consider the case where $0<\gamma^{N}<\gamma^{S}$ but it would make the analysis much more complex without changing qualitatively the results.
} 
By combining equation (6) with (8), factor returns can be expressed as follows:

$$
R_{t}^{i}=\Psi^{i}\left(G_{t}\right) A_{b}^{i} \alpha_{b} \Lambda_{b}^{\alpha_{b}-1}\left(\frac{A_{g}^{i}}{A_{b}^{i}}\right)^{\frac{\alpha_{b}-1}{\alpha_{b}-\alpha_{g}}}\left(p_{g, t}^{i}\right)^{\frac{\alpha_{g}-1}{\alpha_{b}-\alpha_{g}}} \quad ; \quad w_{t}^{i}=\Psi^{i}\left(G_{t}\right) A_{b}^{i}\left(1-\alpha_{b}\right) \Lambda_{b}^{\alpha_{b}}\left(\frac{A_{g}^{i}}{A_{b}^{i}}\right)^{\frac{\alpha_{b}}{\alpha_{b}-\alpha_{g}}}\left(p_{g, t}^{i}\right)^{\frac{\alpha_{g}}{\alpha_{b}-\alpha_{g}}}
$$

We easily identify the Stolper Samuelson theorem such that when the relative price of the good $g$ decreases, the return of the factor intensively used to produce this good decreases, while the return of the other factors increases. Therefore, under Assumption 1, the relative price of the green good has a negative effect on capital return and a positive effect on wage.

Using equation (7) and the full-employment conditions for factors i.e. $K_{t}^{i}=k_{b, t}^{i} L_{b, t}^{i}+k_{g, t}^{i} L_{g, t}^{i}$, we can express the labor used in the green sector $L_{g, t}^{i}$ and in the brown sector $L_{b, t}^{i}$ as:

$$
L_{g, t}^{i}=\frac{\left(1-\alpha_{g}\right) \alpha_{b}\left(k_{b, t}^{i}-K_{t}^{i}\right)}{k_{b, t}^{i}\left(\alpha_{b}-\alpha_{g}\right)}, L_{b, t}^{i}=\frac{\alpha_{b}\left(1-\alpha_{g}\right) K_{t}^{i}-k_{b, t}^{i} \alpha_{g}\left(1-\alpha_{b}\right)}{k_{b, t}^{i}\left(\alpha_{b}-\alpha_{g}\right)}
$$

\subsection{Households}

We consider an overlapping generations economy. At each date $t$, a new generation of identical agents is born. We assume no population growth and we normalize to 1 the population size of each generation. Households in each region live for two periods - youth and old age. A representative agent born in period $t$ cares about her/his consumption when young and old $\left(c_{t}^{i}\right.$ and $d_{t+1}^{i}$, respectively). Her/his preferences are described by the following utility function:

$$
U\left(c_{t}^{i}, d_{t+1}^{i}\right)=\ln c_{t}^{i}+\beta \ln d_{t+1}^{i}
$$

where $\beta \in(0,1]$ denotes the individual preference rate for the future.

When young, the agent supplies inelastically one unit of labor remunerated at wage $w_{t}^{i}$. She/he allocates her/his income in consumption $c_{t}^{i}$ and in savings $s_{t}^{i}$. When old, she/he is retired and uses entirely the return on her/his savings $R_{t+1}^{i} s_{t}^{i}$ to consume $d_{t+1}^{i}$. Therefore, the representative agent solves the following dynamic program:

$$
\max _{c_{t}^{i}, d_{t+1}^{i}, s_{t}^{i}}\left\{\ln c_{t}^{i}+\beta \ln d_{t+1}^{i} \mid p_{g, t}^{i} c_{t}^{i}+s_{t}^{i}=w_{t}^{i}, p_{g, t+1}^{i} d_{t+1}^{i}=s_{t}^{i} R_{t+1}^{i}\right\}
$$

Solving the first-order conditions gives the standard agent's optimal choices:

$$
s_{t}^{i}=\frac{\beta}{1+\beta} w_{t}^{i}, \quad p_{g, t}^{i} c_{t}^{i}=\frac{1}{1+\beta} w_{t}^{i}, \quad p_{g, t+1}^{i} d_{t+1}^{i}=\frac{\beta}{1+\beta} R_{t+1}^{i} w_{t}^{i}
$$




\section{Free trade equilibrium}

The world economy is composed of two regions, in which there is free trade in the brown and the green goods, while production factors (labor and capital) are immobile across regions. In other words, we assume that new units of capital are tradable, as the good used to invest in physical capital is free to move, but that the existing stock of capital is not. ${ }^{5}$

The two regions differ in terms of sectoral TFP and of vulnerability to climate change damages. Under free trade in the output of the green and the brown sectors, the relative price of the green good in terms of the brown good at each $t$ is common to both regions and denoted $p_{g, t}^{W}$. Following Assumption 2, we denote for the rest of the analysis $\Psi^{N}=1$ and $\Psi^{S}=\Psi$.

\subsection{Intertemporal equilibrium}

We define an intertemporal diversified equilibrium.

Definition 1. Given the initial conditions $K_{t=0}^{i}$ and $G_{t=0}{ }^{6}$, a perfect-foresight diversified competitive equilibrium is the sequence $\left\{K_{t}^{i}, G_{t}\right\}_{t=0}^{\infty}$ such that, for all $t \geqslant 0$ :

$i\rfloor$ Factor prices are given by (6) and are identical in both sectors;

ii」 Households are at their optimum: The first-order conditions given by (13) are satisfied;

iii」 The physical capital accumulation equation is given by $K_{t+1}^{i}=s_{t}^{i}{ }^{7}$

$i v\rfloor$ Equation (2) gives the equilibrium value of the pollution flow;

$v\rfloor$ The market clearing condition for the brown good is given by $Y_{b, t}^{N}+\Psi\left(G_{t}\right) Y_{b, t}^{S}=s_{t}^{N}+s_{t}^{S}$;

$v i\rfloor$ The equilibrium is diversified in each region $L_{j, t}^{i} \in(0,1)$.

From the production functions defined in (1) and the optimal choices of consumers (13), the equilibrium condition on the brown good market $(v\rfloor$ in Definition 1$)$ can be rewritten as:

$$
A_{b}^{N} L_{b, t}^{N}\left(k_{b, t}^{N}\right)^{\alpha_{b}}+A_{b}^{S} L_{b, t}^{S}\left(k_{b, t}^{S}\right)^{\alpha_{b}} \Psi\left(G_{t}\right)=\frac{\beta}{1+\beta}\left(w_{t}^{N}+w_{t}^{S}\right)
$$

From (6) and (8), it follows that the behavior of the two trading economies over time is determined by the evolution of the world relative price $p_{g, t}^{W}$ and of the global stock of GHG $G_{t}$ both commons to the two regions.

\footnotetext{
${ }^{5}$ Following Yenokyan et al. (2014), it means that once the investment has been put in place, the resulting stock is not mobile. Note that this is the standard specification in the dynamic trade model with two tradable goods, since Oniki and Uzawa (1965).

${ }^{6}$ Initial conditions on $K_{t=0}^{i}$ and $G_{t=0}$ imply that $p_{g, t=0}^{W}$ is given.

${ }^{7}$ Capital depreciates fully in a period such that the stock in $t+1$ is just given by the amount of savings in $t$.
} 
Lemma 1. The dynamics of the world diversified economy is driven by the following equations:

$$
\begin{gathered}
\left(\frac{\left(p_{g, t}^{W}\right)_{b}^{\alpha_{b}}}{p_{g, t+1}^{W}}\right)^{\frac{1}{\alpha_{b}-\alpha_{g}}}=\frac{\frac{\beta \alpha_{b}+\alpha_{g}}{\beta \alpha_{b}\left(1-\alpha_{g}\right)}\left(1+(B)^{\frac{\alpha_{g}}{\alpha_{b}-\alpha_{g}}}\left(\frac{1}{T}\right)^{\frac{\alpha_{b}}{\alpha_{b}-\alpha_{g}}} \Psi\left(G_{t}\right)\right)}{x\left(1+\left(\frac{1}{B}\right)^{\frac{1-2 \alpha_{g}}{\alpha_{b}-\alpha_{g}}}(T)^{\frac{1-2 \alpha_{b}}{\alpha_{b}-\alpha_{g}}} \Psi\left(G_{t}\right)^{2}\right)} \\
G_{t+1}=(1-\eta) G_{t}+\left(A_{b}^{N}\right)^{\frac{1}{1-\alpha_{b}}}\left(p_{g, t}^{W}\right)^{\frac{\alpha_{b}}{\alpha_{b}-\alpha_{g}}} x^{\frac{\alpha_{b}}{\alpha_{b}-1}} \theta L_{b, t}^{N}+\Lambda_{b}^{\alpha_{b}}\left(p_{g, t}^{W}\right)^{\frac{\alpha_{b}}{\alpha_{b}-\alpha_{g}}} A_{b}^{S}\left(\frac{A_{g}^{S}}{A_{b}^{S}}\right)^{\frac{\alpha_{b}}{\alpha_{b}-\alpha_{g}}} \theta L_{b, t}^{S}
\end{gathered}
$$

with $T \equiv \frac{A_{g}^{N}}{A_{g}^{S}}, B \equiv \frac{A_{b}^{N}}{A_{b}^{S}}, x \equiv A_{b}^{N}\left(\frac{A_{b}^{N}}{A_{g}^{N}}\right)^{\frac{1-\alpha_{b}}{\alpha_{b}-\alpha_{g}}} \Lambda_{b}^{\alpha_{b}-1}$ and

$$
\begin{aligned}
& L_{b, t+1}^{N}=\frac{\left(1-\alpha_{b}\right)}{\left(\alpha_{b}-\alpha_{g}\right)}\left[-\alpha_{g}+\frac{\alpha_{b} \beta}{1+\beta}\left(1-\alpha_{g}\right) x\left(\frac{\left(p_{g, t}^{W}\right)^{\alpha_{b}}}{p_{g, t+1}^{W}}\right)^{\frac{1}{\alpha_{b}-\alpha_{g}}}\right] \equiv L_{b}^{N}\left(T, G_{t}\right) \\
& L_{b, t+1}^{S}=\frac{\left(1-\alpha_{b}\right)}{\left(\alpha_{b}-\alpha_{g}\right)}\left[-\alpha_{g}+\frac{\alpha_{b} \beta}{1+\beta}\left(1-\alpha_{g}\right) x\left(\frac{T^{1-\alpha_{b}}}{B^{1-\alpha_{g}}}\right)^{\frac{1}{\alpha_{b}-\alpha_{g}}}\left(\frac{\left(p_{g, t}^{W}\right)^{\alpha_{b}}}{p_{g, t+1}^{W}}\right)^{\frac{1}{\alpha_{b}-\alpha_{g}}} \Psi\left(G_{t}\right)\right] \equiv L_{b}^{S}\left(T, G_{t}\right)
\end{aligned}
$$

where $\partial L_{b}^{N} / \partial T<0$ and $\partial L_{b}^{S} / \partial T>0$. Moreover, we have that $\partial L_{b}^{S} / \partial G_{t}<0$ and $\partial L_{b}^{N} / \partial G_{t}>0$ when $0<L_{b}^{S}\left(T, G_{t}\right), L_{b}^{N}\left(T, G_{t}\right)<1$, and that $\lim _{G_{t} \rightarrow \infty} L_{b}^{S}\left(T, G_{t}\right)<0$ and $\lim _{G_{t} \rightarrow \infty} L_{b}^{N}\left(T, G_{t}\right)>0$.

Proof. See Appendix 6.1.

In this model, trade results from two forces. The first is the standard Ricardian force, such that a region has a comparative advantage in the sector in which it is relatively more productive. The second force emerges from the relative "endowments" of the production factors. While countries are assumed to have the same exogenous labor endowment $L^{N}=L^{S}=1$, physical capital is produced and accumulated over time according to the country's TFP and its vulnerability to climate change. The two regions are thus differing in their capital stock for all $t>0$, even if they start with the same capital endowment.

Figure 1 illustrates how global pollution impacts the capital stock in the South. Pollution leads to damages in the South economy, meaning that the net outputs of the southern firms in both sectors decrease. Thus, their profits and the remuneration of the factors they use are all affected negatively. As damages from climate change reduce the wage of southern workers, it diminishes also their ability to save and the stock of capital in the South. In this way, the level of global pollution modify the relative capital abundance between countries, which in turn will modify the world relative price of goods. ${ }^{8}$

\footnotetext{
${ }^{8}$ The mechanisms linking the world relative price $p_{g}^{W}$ to pollution are further detailed in Section 4.1.
} 


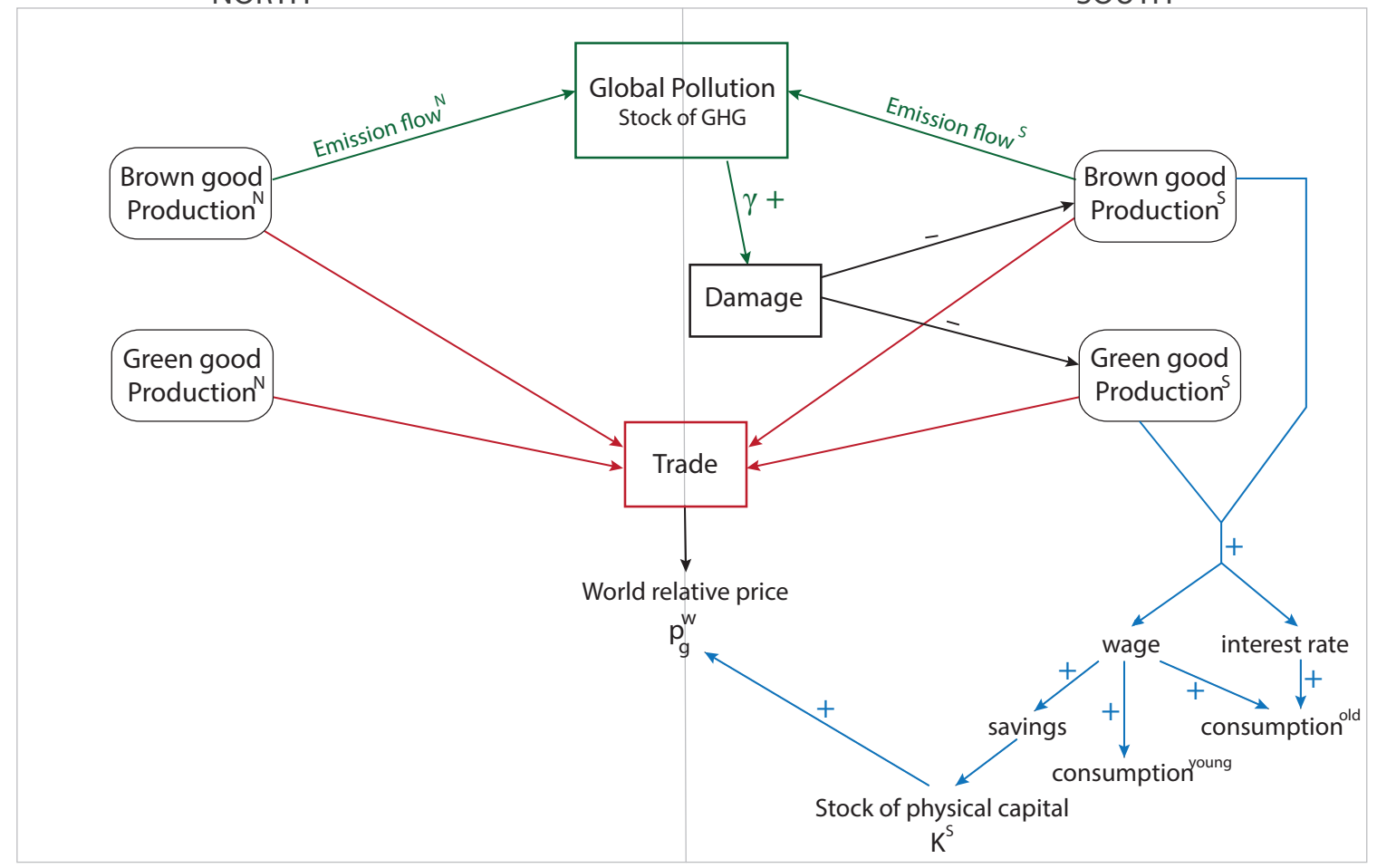

Figure 1: Structure of the model

Without loss of generality, we restrict our analysis to the relevant case in which production is diversified in both regions and the North is a net exporter of the green production when there is no climate change damage. ${ }^{9}$ Thus, from Lemma 1, we assume the following.

Assumption 3. Using (17), we define $T_{1}^{i}$ and $T_{2}^{i}$ as $L_{b}^{i}\left(T_{1}^{i}, 0\right)=0$ and $L_{b}^{i}\left(T_{2}^{i}, 0\right)=1$. We assume $T \in(\underline{T}, \bar{T})$ with $\underline{T}=B^{\frac{1-\alpha_{g}}{1-\alpha_{b}}}$ and $\bar{T}=\min \left\{T_{2}^{S}, T_{1}^{N}\right\}$.

This assumption has two main implications. First, $T>\underline{T}$ ensures that in the absence of damage, the country relatively more productive in the green sector is a net exporter of this good, i.e. the Ricardian law of comparative advantage holds. ${ }^{10} \mathrm{~A}$ condition is required to satisfy this law because when North is more productive in both sectors with a comparative advantage in the green one, it accumulates more capital than South and has therefore an incentive to specialize in the capital intensive (polluting) production. Thus, in order to ensure a comparative advantage of North in green industries, capital intensity differences between the brown and the green sector

\footnotetext{
${ }^{9}$ We leave aside the case in which one of the country is perfectly specialized, as considering the corner case with perfect specialization does not change the results and just makes the analysis much more burdensome.

${ }^{10}$ This condition implies $L_{b}^{S}(T, 0)>L_{b}^{N}(T, 0)$.
} 
has to be not too large $\left(\alpha_{b}-\alpha_{g}\right.$ low $)$ with respect to the relative TFP advantage in the green sector for North $(T / B$ large).

Second, $T<\bar{T}$ means that cross-country TFP differences are not too large so that both countries produce both goods in the absence of damage. For the rest of the analysis, we will focus on an equilibrium in which production remains diversified with pollution damages, i.e. $L_{j, t}^{i} \in(0,1)$. For this purpose, using Lemma 1, we define $G_{1}$ and $G_{2}$ as $L_{b}^{S}\left(T, G_{1}\right)=0$ and $L_{b}^{N}\left(T, G_{2}\right)=1$ respectively, and consider the case in which:

$$
G_{t}<\Omega ; \text { with } \Omega=\min \left\{G_{1}, G_{2}\right\}
$$

This condition on pollution does not imply that the North has always a comparative advantage in the green production. As pollution evolves across time, so can comparative advantages.

\subsection{Steady state}

At the steady state, the stock variables achieve a stationary level and the world relative price of the green good is constant. Denoting $\bar{G}$ and $\bar{p}_{g}^{W}$, the steady state level of pollution and the steady state world relative price respectively, we get from Lemma 1:

Lemma 2. Under Assumptions 1-3, the steady state of the world economy is characterized by the following set of equations:

$$
\begin{gathered}
\bar{p}_{g}^{W}=(\bar{G})^{\frac{\alpha_{b}-\alpha_{g}}{\alpha_{b}}}\left(\frac{\theta}{\eta} \frac{\left(1-\alpha_{b}\right)}{\left(\alpha_{b}-\alpha_{g}\right)}\left(A_{b}^{N}\right)^{\frac{1}{1-\alpha_{b}}}\right)^{\frac{-\alpha_{b}+\alpha_{g}}{\alpha_{b}}} \times \\
\left(\frac{\left(\beta \alpha_{b}+\alpha_{g}\right) \Upsilon(\bar{G})}{(1+\beta)}\left[1+\Psi(\bar{G})\left(\frac{B}{T}\right)^{\frac{1}{\alpha_{b}-\alpha_{g}}}\right]-\alpha_{g}\left[1+\left(\frac{B^{\alpha_{g}}}{T^{\alpha_{b}}}\right)^{\frac{1}{\alpha_{b}-\alpha_{g}}}\right]\right)^{\frac{-\alpha_{b}+\alpha_{g}}{\alpha_{b}}} \\
\bar{p}_{g}^{W}=\left(\frac{\beta \alpha_{b}+\alpha_{g}}{x \beta \alpha_{b}\left(1-\alpha_{g}\right)} \Upsilon(\bar{G})\right)^{\frac{\alpha_{b}-\alpha_{g}}{\alpha_{b}-1}} \\
\bar{G}<\Omega
\end{gathered}
$$

with

$$
\Upsilon(\bar{G})=\frac{1+\Psi(\bar{G})\left(\frac{B^{\alpha_{g}}}{T^{\alpha_{b}}}\right)^{\frac{1}{\alpha_{b}-\alpha_{g}}}}{1+(\Psi(\bar{G}))^{2}\left(\frac{1}{B}\right)^{\frac{1-2 \alpha_{g}}{\alpha_{b}-\alpha_{g}}}(T)^{\frac{1-2 \alpha_{b}}{\alpha_{b}-\alpha_{g}}}}
$$


From this lemma, we study the existence and the unicity of a steady state equilibrium and derive the following result:

Proposition 1. Let $\bar{G} \equiv G(\gamma)$ and $\Omega \equiv \Omega(\gamma)$. Under Assumptions 1-3, there exists a threshold $\bar{\gamma}$ such that $G(\bar{\gamma})=\Omega(\bar{\gamma})$. For $\gamma<\bar{\gamma}$, the world economy achieves a steady state equilibrium in which both economies are diversified.

Proof. See Appendix 6.2

In line with the aforementioned mechanism, a high vulnerability of the South to climate change would prevent it to produce the capital intensive good. Therefore, $\gamma$ has to be not too high to guarantee that both economies still produce both goods at the steady state, even in the presence of pollution.

\section{Welfare analysis}

This section explores how the welfare of consumers in a country that is not directly vulnerable to climate change, i.e. the North, may be affected by the climate damages occurring in other countries, i.e. the South. Such a welfare analysis enables us to examine carefully the indirect effects of climate change on developed countries that occur through international trade, in addition to its existing direct consequences.

In an international trade context, an event occurring in one country will be felt by all regions of the trading area once the event modifies the prices on international market. As a result, a damage that destroys a part of production in the South affects its trading partners through the modification in the world relative price $p_{g}^{W}$ it entails. The welfare in the North economy therefore evolves with the global stock of pollution. In the following sections, we wonder what are the implications of pollution for the lifetime utility of a representative northern consumer in both the short and the long run.

\subsection{Short-run implications}

In this section, we wonder how the welfare of successive northern generations evolve over time when the South is vulnerable to climate change.

Using the demand functions given by (13) and expressing factor prices with (9), the northern 
agents' welfare - indirect utility - is given by the following function:

$$
V^{N}\left(p_{g, t}^{W}, p_{g, t+1}^{W}\right)=\mathcal{C}_{1}+\left(\frac{\alpha_{g}+\alpha_{b} \beta}{\alpha_{b}-\alpha_{g}}\right) \ln \left(p_{g, t}^{W}\right)-\beta\left(\frac{1-\alpha_{g}}{\alpha_{b}-\alpha_{g}}\right) \ln \left(p_{g, t+1}^{W}\right)
$$

with $\mathcal{C}_{1}$ a constant whose value is given in Appendix 6.3.

From equation (23), we see that the lifetime income of an agent born at time $t$ depends positively on the world relative price of good $g$ at time $t$ and negatively on the world relative price of good $g$ at time $t+1$. This is because income during working period is driven by the return of labor at time $t$, which increases with $p_{g, t}^{W}$, while income during the retirement period depends on the return of capital at time $t+1$, which decreases with $p_{g, t+1}^{W}$. Using equation (15), we can define the relative price at time $t+1$ as a decreasing function of the pollution stock at time $t$ because the latter reduces the stock of capital in $t+1$. Indeed, as summarized in Figure 1, the global pollution $G_{t}$ entails damages that affect negatively the current net output of southern firms and hence the wages they pay to workers $w_{t}^{S}$. In this way, southern workers' savings $s_{t}^{S}$ and the resulting capital stock in this region $K_{t+1}^{S}$ fall. The capital becoming more scarce in the South, the world relative price of the capital intensive good $b$ increases, meaning that the world relative price of the green good $p_{g, t+1}^{W}$ decreases. It entails that the return of capital $R_{t+1}$ in the North goes up with pollution. The lifetime income of a northern agent born in $t$ is therefore an increasing function of the relative price of good $g$ and of the pollution stock. We can rewrite the indirect utility function by using equation (15):

$$
V^{N}\left(p_{g, t}^{W}, G_{t}\right)=\mathcal{C}_{2}+\left(\alpha_{g} \frac{1+\alpha_{b} \beta}{\alpha_{b}-\alpha_{g}}\right) \ln \left(p_{g, t}^{W}\right)+\beta\left(1-\alpha_{g}\right) \ln \left(\Upsilon\left(G_{t}\right)\right)
$$

with $\mathcal{C}_{2}$ a constant whose value is given in Appendix 6.3 and

$$
\Upsilon\left(G_{t}\right)=\left[\frac{1+\left(\frac{T}{B}\right)^{\frac{1}{\alpha_{b}-\alpha_{g}}}\left(\frac{B^{\alpha_{g}}}{T^{\alpha_{b}}} \Psi\left(G_{t}\right)\right)^{2}}{1+\left(\frac{B}{T}\right)^{\frac{1}{\alpha_{b}-\alpha_{g}}}\left(\frac{B^{\alpha_{g}}}{T^{\alpha_{b}}}\right) \Psi\left(G_{t}\right)}\right]
$$

The evolution of northern agents' welfare across generations is driven by the transitional dynamics of the world relative price and of the pollution stock. From the dynamical system presented in Lemma 1 and after defining the two loci GG $\equiv\left\{\left(p_{g, t}^{W}, G_{t}\right): G_{t+1}=G_{t}\right\}$ and PP $\equiv\left\{\left(p_{g, t}^{W}, G_{t}\right): p_{g, t+1}^{W}=p_{g, t}^{W}\right\}$, the transitional dynamics can be depicted in the following phase diagram (see details in Appendix 6.3): 


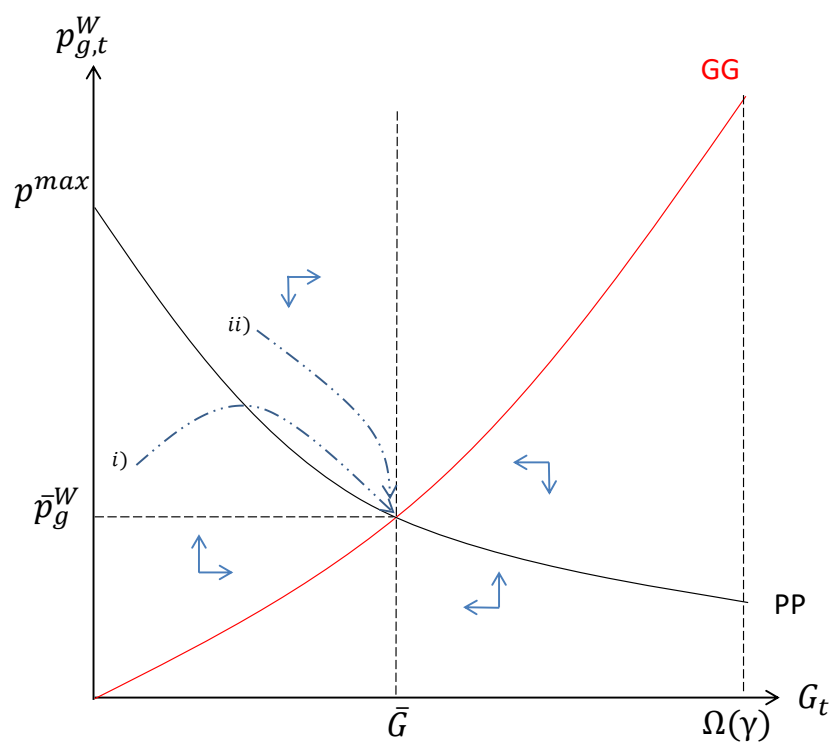

Figure 2: Phase diagram with $\gamma \in(0, \bar{\gamma})$

We consider the standard initial conditions such that, in the absence of damage, the relative price of the capital intensive good decreases over time due to the capital accumulation process, meaning that $p_{g}^{W}$ increases. ${ }^{11}$ We show that this usual dynamics does not necessarily hold anymore because of the negative impact of pollution on the stock of physical capital. As illustrated in the phase diagram, when the initial level of pollution is not too high $(G<\bar{G})$ and the initial relative price is between $\bar{p}_{g}^{W}$ and $p^{\max }$, the continuous upward trend of the world relative price of the green good no longer occurs. More precisely, we observe that, while pollution is still increasing over time, the relative price of $g$ can either increase for some periods and then falling over time, or decrease for all periods along the convergence to the long-term state. This downward trend of the world relative price comes from the fact that the negative effect of pollution on the price through damages overtakes the direct positive effect of capital accumulation over time.

Having examined the dynamics of the variables driving the indirect utility of northern agents, we can study the evolution of the welfare of successive northern generations over time.

Proposition 2. Under Assumptions 1-3 and $\gamma<\bar{\gamma}$, there exists a set of initial conditions $K_{0}^{N}$, $K_{0}^{S}$ and $G_{0}$ such that, when $\beta$ is sufficiently low, the welfare of successive generations is $i$ ) first increasing but then falling over time, or ii) always decreasing over time.

Proof. Directly obtained using the phase diagram depicted in Figure 2 with equation (24).

\footnotetext{
${ }^{11}$ In absence of pollution damage $\gamma=0$, the PP locus is an horizontal line defined by $p^{\max } \equiv \bar{p}_{g}^{W}$ and the dynamics of both pollution and the relative price are always increasing as long as initial conditions on capital stock and pollution define an economy with $p_{0}^{W}<\bar{p}_{g}^{W}$ and $G_{0}<\bar{G}$.
} 
When the transitional path follows an upward trend in both pollution and the world price of the green good, the utility of successive generations is increasing over time. However, when the transitional path exhibits an increasing pollution and a decreasing world price of $g$, two competing effects on northern agents' welfare are at work. The decrease in the world relative price of goods harms their welfare by reducing their wages, while the increase in pollution improves it by increasing the returns on savings. When agents are very patient ( $\beta$ high), they highly value their consumption during retirement and hence the utility of successive generations is still increasing along the transitional path even though environmental quality and the relative price of goods are deteriorating. However, when agents are sufficiently impatient ( $\beta$ low), the South's vulnerability prevents the continuous improvement of welfare in the North economy and the welfare of successive generations is actually falling. ${ }^{12}$

The fact that the welfare of northern generations is falling over time characterizes intergenerational inequity as the lifetime utility of a given generation is lower than those of the previous generations. This result reveals that, in an international trade context, climate change can cause intergenerational inequity even in an economy that would be completely preserved from its direct negative consequences.

Corollary 1. Under Assumptions 1-3 and $\gamma<\bar{\gamma}$, there exists a set of initial conditions $K_{0}^{N}$, $K_{0}^{S}$ and $G_{0}$ such that, when $\beta$ is sufficiently low, the higher vulnerability of the South to climate change is a source of intergenerational inequity in the North.

\subsection{Long-run implications}

In the long run, the economy achieves a stationary state in which the global stock of GHG and the stock of capital are stabilized. The welfare of all generations are thus identical at this state, meaning that there is no intergenerational inequity issue anymore. However, the long-term analysis enables us to have a full picture of how the South's vulnerability to pollution affects the northern agents' welfare. In this section, we examine the impact of a permanent and unexpected increase in the South's vulnerability $\gamma$ on the welfare of a northern generation, once the final steady state is achieved.

For that, we evaluate the indirect utility function (23) at the initial steady state and we totally differentiate the expression with respect to $\gamma$. Welfare effects are given by the following

\footnotetext{
${ }^{12}$ If we consider that the North is directly vulnerable to climate change, an additional negative effect on wages and interest rates would exist. Thus, it would make the decrease in the welfare of successive generations more likely.
} 
$\operatorname{expression}^{13}$ :

$$
\operatorname{sgn} \frac{d V^{N}}{d \gamma}=\left(K^{N}-Y_{b}^{N}\right) \frac{\partial p_{g}^{W}}{\partial \gamma}+\frac{K^{N}\left(R^{N}-1\right)\left(1-\alpha_{g}\right)}{\alpha_{b}-\alpha_{g}} \frac{\partial p_{g}^{W}}{\partial \gamma}
$$

The consequences of the South's vulnerability on northern agents' welfare consist in two effects, going through variations in the world relative price of the green good: a terms of trade effect (or ToT effect), captured by the first term of equation (25), and a dynamic (in)efficiency effect (or DyE effect), captured by the second term of equation (25). We are going to study the direction and the magnitude of these two effects in the following subsections.

\subsubsection{Terms of trade effect}

The terms of trade effect depends on the specialization of regions. A net exporter of the green good suffers from a decrease in the world relative price of this good, while a net importer benefits from it.

We determine the pattern of trade in the presence of pollution costs, by studying the net position of the North in regard to its exports of the brown good, denoted by $e_{b}^{N}$ and equal to $\operatorname{sgn}\left(Y_{b}^{N}-K^{N}\right)$. Using equations (1), (6) (13), (15) and (17), we obtain ${ }^{14}$ :

$$
e_{b}^{N}=-e_{b}^{S}=\left[(B)^{\frac{1-\alpha_{g}}{\alpha_{b}-\alpha_{g}}}-(T)^{\frac{1-\alpha_{b}}{\alpha_{b}-\alpha_{g}}} \Psi(\gamma)\right] \equiv e_{b}^{N}(\gamma)
$$

The vulnerability of the South to climate change $\gamma$ has therefore a clear impact on the specialization of countries. More precisely, letting $\varepsilon_{G / \gamma}=\frac{\partial G(\gamma)}{\partial \gamma} \frac{\gamma}{G(\gamma)}$ the elasticity of the stationary stock of pollution to the South's vulnerability, we derive the following proposition.

Proposition 3. Under Assumptions 1-3 and $\left|\varepsilon_{G / \gamma}\right|<1 / 2$, there exists a threshold $\hat{\gamma}(\beta) \in(0, \bar{\gamma})$ such that $e_{b}^{N}(\hat{\gamma}(\beta))=0$. At the long-term equilibrium, North is a net exporter of the green good if $\gamma<\hat{\gamma}(\beta)$, and of the brown good if $\hat{\gamma}(\beta)<\gamma<\bar{\gamma}$.

Proof. See Appendix 6.5

The elasticity of the stationary pollution stock $\bar{G}(\gamma)$ to the South's vulnerability $\gamma$ has to be sufficiently low to ensure that an increase in vulnerability positively affects the damage in the

\footnotetext{
${ }^{13}$ Details are provided in Appendix 6.4.

${ }^{14}$ For the rest of the analysis, we define $\Psi(\gamma, \bar{G}(\gamma)) \equiv \Psi(\gamma)$.
} 
South economy along the steady state $(\partial \Psi(\gamma) / \partial \gamma<0)$. Given this, we reveal that the magnitude of natural disasters, captured by $\gamma$, alters the specialization of countries along the steady state. This result is due to two effects of $\gamma$ on the capital stock of regions, represented by the following expressions. ${ }^{15}$

$K^{N}=\frac{\beta}{1+\beta}\left(1-\alpha_{b}\right) A_{b}^{N}\left(\frac{\bar{p}_{g}^{W} A_{g}^{N}}{A_{b}^{N}}\right)^{\frac{\alpha_{b}}{\alpha_{b}-\alpha_{g}}} \Lambda_{b}^{\alpha_{b}} ; \quad K^{S}=\Psi(\gamma) \frac{\beta}{1+\beta}\left(1-\alpha_{b}\right) A_{b}^{S}\left(\frac{\bar{p}_{g}^{W} A_{g}^{S}}{A_{b}^{S}}\right)^{\frac{\alpha_{b}}{\alpha_{b}-\alpha_{g}}} \Lambda_{b}^{\alpha_{b}}$

First, an increase in the South's vulnerability $\gamma$ has a direct effect on the South (through $\Psi(\gamma))$. Provided that $\left|\varepsilon_{G / \gamma}\right|<1 / 2, \gamma$ acts as a negative productivity effect that translates into a fall in wages, hence reducing savings and the accumulation of physical capital in this region. Second, as capital becomes more scarce in the South, the world relative price of the capital intensive good (i.e. b) increases, or equivalently the world relative price of the green good decreases $\left(\partial p_{g}^{W} / \partial \gamma<0\right)$. Therefore, it harms agents' wages and implies a fall in their savings and in the capital stock in both regions. In fine, the capital stock of each region is affected negatively by the climate damages occurring in the South but the degradation is worse in this latter region. As a result, the North becomes relatively more capital abundant when the South's vulnerability to climate change increases.

When $\gamma$ is high enough (i.e. $\gamma>\hat{\gamma}(\beta)$ ), the capital scarcity of the South is so large that the North has a comparative advantage in the polluting - capital intensive - sector. Even if the North is relatively more productive in the non-polluting sector, when environmental disasters are sufficiently important the capital "endowment" differences are much stronger and become the main determinant of specialization. Therefore, damages from climate change distort the allocation of resources in favor of the green production in the South, and of the brown production in the North. Even if free trade is a way to efficiently allocate resources, the presence of pollution costs can imply that the allocation of resources does not necessarily correspond to the intuitive situation where countries are specialized in the sector in which they have the highest relative productivity.

Note that the threshold $\hat{\gamma}(\beta)$, from which the comparative advantage of the North changes, depends on the preferences for the future $\beta$. The more agents value their consumption when old, the higher their capital accumulation and hence the higher the pollution stock. Thus, $\beta$ favors the negative effect on the South and hence the North's specialization in the brown production

\footnotetext{
${ }^{15}$ These expressions are obtained from the capital market equilibrium in each country and equation (8) along the steady state.
} 
$(\hat{\gamma}(\beta)$ goes down with $\beta)$.

Knowing the specialization of regions, we can describe the sign of the terms of trade effect, going through the fall in the world relative price of the green good, and its implications in terms of welfare. This is the purpose of the following proposition.

Proposition 4. Under Assumptions 1-3, $\left|\varepsilon_{G / \gamma}\right|<1 / 2$ and $\gamma<\bar{\gamma}$, when $\gamma<\hat{\gamma}(\beta)$ (resp. $\gamma>$ $\hat{\gamma}(\beta))$, the northern agents' welfare decreases (resp. increases) through the terms of trade channel when the South's vulnerability $\gamma$ goes up.

\section{Proof. See Appendix 6.5}

The sign of the terms of trade effect depends on the level of the South's vulnerability $\gamma$. When the South's vulnerability is low, the North is a net exporter of the green good $g$ in the long run, so that the decrease in the relative price of $g$ deteriorates its terms of trade and hence the welfare of northern agents. Reversely, when the South's vulnerability is high, the North is a net exporter of the brown good $b$ so that the decrease in the relative price of $g$ improves its terms of trade and its welfare.

\subsubsection{Dynamic (in)efficiency effect}

The dynamic (in)efficiency effect depends on the dynamic efficiency properties of the North's competitive equilibrium. To examine it, we pay a particular attention to the northern capital stock that maximizes the social welfare in the North, i.e. satisfying $R^{N}=1 .{ }^{16}$ With overlapping generations, an increase in capital accumulation in the long run contributes positively to agents' welfare only if there is dynamic efficiency, while it is damaging otherwise. Dynamic efficiency corresponds to situations in which the savings rate of agents is low, meaning that they underinvest in capital compare to the socially optimal solution. An increase in capital accumulation therefore enhances agents' welfare in this case. However, as shown previously, damages from climate change occurring in the South lead to a decrease in the world relative price of the green good, which reduces northern workers' wages and their ability to save. In this way, the South's vulnerability to climate change harms the capital accumulation in the North and affects the northern agents' welfare. That is what we call the dynamic (in)efficiency effect, whose direction is summarized in the following proposition.

\footnotetext{
${ }^{16}$ We consider that an efficient allocation of resources in the North is given by the solution of a social planner program that consists in maximizing the welfare of northern agents when all northern generations are treated equally (i.e. the social discount factor is equal to zero). In absence of population growth, the optimal stationary capital ratio is such that the marginal product of capital is equal to 1 .
} 
Proposition 5. Let $\tilde{K}^{N}$ being the efficient stock of capital in the North and $K^{N} \equiv K^{N}(\beta, \gamma)$. Under Assumptions 1-3, $\left|\varepsilon_{G / \gamma}\right|<1 / 2$ and $\gamma<\bar{\gamma}$, there exists a threshold $\tilde{\gamma}(\beta)$ such that $K^{N}(\beta, \tilde{\gamma}(\beta))=\tilde{K}^{N}$. When $\gamma>\tilde{\gamma}(\beta)$ (resp. $\gamma<\tilde{\gamma}(\beta)$ ), the welfare in the North economy decreases (resp. increases) through the dynamic (in)efficiency effect when the South's vulnerability to global pollution $\gamma$ goes up.

Proof. See Appendix 6.6.

On one hand, the condition $\gamma>\tilde{\gamma}(\beta)$ corresponds to the case in which the North economy is at a dynamically efficient equilibrium, or in other words in which the stock of capital is lower than the capital maximizing northern social welfare. In this case, an increase in the South's vulnerability reinforces the existing under-accumulation of capital in the North compared to the optimal allocation, which entails that northern agents' welfare deteriorates.

On the other hand, when the North is at a dynamically inefficient equilibrium $(\gamma<\tilde{\gamma}(\beta))$, damages in the South reduce the over-accumulation of capital and we find that it improves northern agents' welfare. The reason is that these agents value a lot their consumption when old (sufficiently to over-accumulate capital) and, by reducing the stock of physical capital, damages increase the return of their savings which benefits them.

The fact that the North is at a dynamically efficient or inefficient equilibrium $(\gamma \lessgtr \tilde{\gamma}(\beta))$ depends logically on individuals' time preference $\beta$. Indeed, this parameter determines the importance agents attached to their future and hence the extent of their savings and their capital accumulation. We can extend Proposition 5 according to this key parameter.

Corollary 2. Under Assumptions 1-3, $\left|\varepsilon_{G / \gamma}\right|<1 / 2$ and $\gamma<\bar{\gamma}$, there exists a threshold $\bar{\beta}$ such that $\tilde{\gamma}(\bar{\beta})=0$. When agents in the world economy are sufficiently impatient with $\beta<\bar{\beta}$, an increase in the South's vulnerability always reduces northern agents' welfare through the dynamic (in) efficiency effect.

Proof. Under Assumptions 1-3, $\left|\varepsilon_{G / \gamma}\right|<1 / 2$ and $\gamma<\bar{\gamma}$, the threshold $\tilde{\gamma}(\beta)$ is increasing with $\beta$ and $\tilde{\gamma}(0)<0$. Thus, there exists a unique threshold $\bar{\beta}$ such that $\tilde{\gamma}(\bar{\beta})=0$. When $\beta<\bar{\beta}$, we have $\tilde{\gamma}(\beta)<0$ and hence the condition to observe a positive dynamic (in)efficiency effect, $\gamma<\tilde{\gamma}(\beta)$, never holds.

As long as northern agents value sufficiently their young age $(\beta<\bar{\beta})$, the North economy under-accumulates physical capital in the absence of damage. As damages harm capital accumu- 
lation, an increase in damages always cause welfare to fall in the North. Therefore, in this case, the vulnerability of the South to climate change always leads to a negative dynamic (in)efficiency effect on their welfare.

On the contrary, when $\beta>\bar{\beta}$, the sign of the dynamic (in)efficiency effect depends on the vulnerability of the South to climate change. Indeed, this condition implies that in the absence of damage, the North over-accumulates capital such that both scenarios can emerge. An increase in climate damages in the South improves or reduces northern agents' welfare, depending on the vulnerability to pollution $\gamma$. Figure 3 illustrates this case, by plotting $\tilde{K}^{N}$ and $K^{N}$ as a function of $\gamma$ when $\beta>\bar{\beta}$. We find that, even when agents' preferences would lead to an over-accumulation of capital in the absence of damage, the dynamic (in)efficiency effect on welfare is negative as long as the vulnerability of the South is sufficiently high.

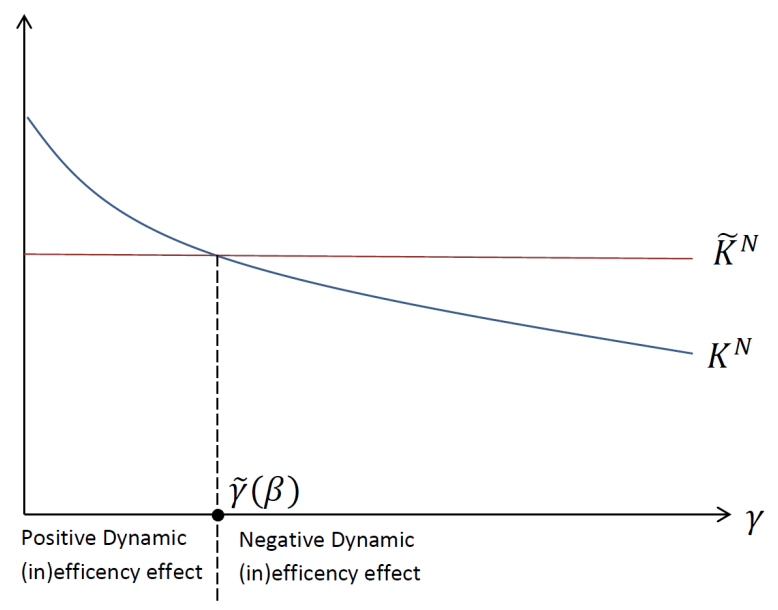

Figure 3: Effect of an increase in $\gamma$ on the North's capital stock for $\gamma<\bar{\gamma}$ and $\beta>\bar{\beta}$.

\subsubsection{Net effect on the long-term welfare}

After examining the two effects through which the South's vulnerability to climate change affects the northern agents' welfare, we wonder about its net aggregate effect. These two effects may oppose or reinforce each other. This section aims at giving some insight into the different possible scenarios in order to determine the net effect of the South's vulnerability on the welfare in the North. For that, we rewrite equation (23), representing the northern agents' welfare, as a function 
of the stationary world relative price $p_{g}^{W}$ only.

$$
V^{N}\left(p_{g}^{W}\right)=\mathcal{C}_{1}+\ln \left(p_{g}^{W}\right)\left(\frac{\alpha_{g}(1+\beta)-\beta\left(1-\alpha_{b}\right)}{\alpha_{b}-\alpha_{g}}\right)
$$

In this way, we clearly identify a condition on $\beta$ that determines the global effect on welfare.

Proposition 6. Under Assumptions 1-3, let $\left|\varepsilon_{G / \gamma}\right|<1 / 2$ and $\gamma<\hat{\gamma}$, there exists a threshold $\hat{\beta}=\alpha_{g} /\left(1-\alpha_{b}-\alpha_{g}\right)$ with $\tilde{\gamma}(\hat{\beta})>0$. When $\beta<\hat{\beta}$ (resp. $\left.\beta>\hat{\beta}\right)$, the welfare of a generation in the non-vulnerable economy, once the final steady state is achieved, decreases (resp. increases) with the South's vulnerability $\gamma$.

Figure 4 summarizes the results presented in Propositions 4 to 6 and in Corollary 2.

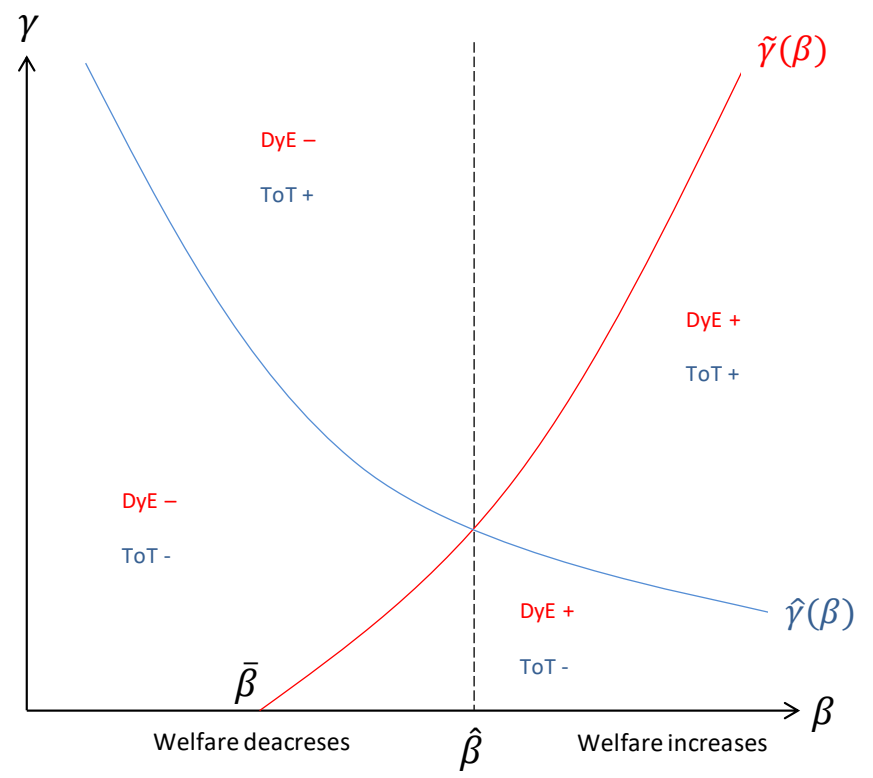

Figure 4: Effect of an increase in $\gamma$ on the welfare in the North for $\gamma<\bar{\gamma}$.

When $\beta=\hat{\beta}$, the long-run welfare in the North does not depend on the South's vulnerability $\gamma$ because the terms of trade and the dynamic (in)efficiency effects exactly offset. However, the damages from climate change in the South are always detrimental to northern agents' welfare as long as they sufficiently value their young age with respect to their old age $(\beta<\hat{\beta})$.

Therefore, we conclude that northern agents would benefit from an action preventing or minimizing the damages from climate change occurring in the South, when agents' preferences for the present is not too low. This recommendation is in line with Schenker and Stephan (2014), 
for whom an adaptation to climate change in the South funded by North may benefit to the donor. However, while this result is conditional upon the fact that the South's vulnerability deteriorates the terms of trade for North in Schenker and Stephan (2014), it holds in our paper even in the case in which the evolution in the terms of trade is in favor of the North.

\section{Conclusion and discussion on policy implications}

This paper explores the consequences of the unequal distribution of climate change damages in the world. Using a multi-sector dynamic general equilibrium model, we discuss how the damages from climate change occurring in a vulnerable country (South) can spill over to a non-vulnerable country (North) through international trade. We identify that the negative effects of global

pollution on the South have also harmful consequences for the North in the short and in the long run, as long as northern agents value sufficiently their welfare when young. In the short run, the damages from climate change in the South can represent a source of intergenerational inequity in the North, in the sense that northern agents' welfare is decreasing over generations. The reason is that natural disasters in the South lead to a negative income effect for southern agents that harms their physical capital accumulation. In this way, damages modify the world relative price of goods and hence northern agents' income. In the long run, low preferences for the future imply that the larger the vulnerability of the South to climate change, the lower will be the long-term welfare toward which the North tends. This negative effect of the damages in the South on the northern economy comes from two possible effects (one of them or both): a deterioration of the terms of trade of the North - whose comparative advantage can evolve with climate change -, and an under-accumulation of capital in the North entailed by the modifications of world prices.

Overall, the international community has become increasingly aware of the importance of public interventions and international cooperation in preventing the welfare loss resulting from climate change. Our analysis reinforces this idea by showing that, in a world with free trade, there can be strong economic incentives for countries - even if their exposure to the direct effects of climate change is low - to fight against this global phenomenon (i.e. invest in mitigation) and to provide assistance to countries that are more vulnerable to climate change (i.e. help them to adapt).

Logically, the questions of the kind of policy to implement and of their acceptability arise. As our model includes relevant elements to examine the indirect welfare effects of pollution in an 
international trade context, we provide a brief discussion about these key issues in the following paragraphs. However, note that in order to formulate detailed policy prescriptions, our setting would require some adjustments, that we leave for future research.

Regarding the policy instruments, the North's action could take the form of contributions to climate funds supporting developing countries' adaptation to climate change and/or of technological transfer programs as the clean development mechanism (CDM) for example. ${ }^{17}$ Regardless the form of the action, it would entail a cost for the North, that would be readily accepted by the population if it is more than compensated by the benefits of exchanging with a country less affected by environmental damages.

However, the distribution of theses benefits can be unequal across time and across population, which can create obstacles to the acceptance of such policies. First, this paper points out that, in the short run, agents do not always perceive the negative effect of abroad damages from climate change at the beginning of the convergence to the long-term state. North may indeed experience an improvement of welfare for some generations, before pollution and the resulting damages become too important and northern agents' welfare declines over time. Consequently, the implementation of these costly measures may generate conflicts between agents living at different periods of time.

Second, as underlined by Karp and Rezai (2014), when looking at the acceptability of a policy, one crucial conflict is those between the different types of agents or generations alive when the policy is first implemented. In this vein, Chiroleu-Assouline and Fodha (2005) examine intergenerational distributional aspects of environmental taxes and determine the conditions to have an environmental reform which is welfare improving for the generations bearing it. We examine this issue in Appendix 6.7 and find that the benefits of an environmental policy introduced by the North may differ between the young and the old generations alive in the North when implementing the policy. We identify conditions such that fewer damages in the South always improve the welfare of the young by increasing their labor income whereas it may decrease the welfare of the elderly by reducing the return on capital. Therefore, a conflict between the two generations can emerge while discussing about the policy implementation, even if its aggregate impact is positive.

Policy measures against climate change, especially those focusing on foreign countries, may face low public support if their benefits are not well perceived. Yet, some economic benefits of

\footnotetext{
${ }^{17}$ In a recent study, Ayong Le Kama and Pommeret (2016) emphasize the importance of devoting money to CDM in order to control emissions abroad and hence to reinforce the efficiency of adaptation measures implemented in the domestic economy.
} 
these policies may exist even for a country relatively sheltered from the direct effects of climate change, as suggest the costs of climate change spreading through trade we show. Given the necessity of public support to establish such a policy and the two potential sources of misperception aforementioned, it appears that assessing clearly the economic benefits associated to the different climate policies represents a key challenge for the future. That is why we think that examining further the economic consequences of a policy preventing or minimizing the damages from climate change abroad in an international trade context is an interesting avenue for future research.

\section{Appendix}

\subsection{Proof of Lemma 1}

Using (6) and (14), we have

$$
L_{b, t}^{N}+\left(\frac{A_{b}^{N}}{A_{b}^{S}}\right)^{\frac{\alpha_{g}}{\alpha_{b}-\alpha_{g}}}\left(\frac{A_{g}^{S}}{A_{g}^{N}}\right)^{\frac{\alpha_{b}}{\alpha_{b}-\alpha_{g}}} \Psi\left(G_{t}\right) L_{b, t}^{S}=\frac{\left(1-\alpha_{b}\right) \beta}{(1+\beta)}\left(1+\left(\frac{A_{b}^{N}}{A_{b}^{S}}\right)^{\frac{\alpha_{g}}{\alpha_{b}-\alpha_{g}}}\left(\frac{A_{g}^{S}}{A_{g}^{N}}\right)^{\frac{\alpha_{b}}{\alpha_{b}-\alpha_{g}}} \Psi\left(G_{t}\right)\right)
$$

From the capital market equilibrium in each country and equation (8), we have

$$
k_{b, t+1}^{N}=\left(\frac{p_{g, t+1}^{W} A_{g}^{N}}{A_{b}^{N}}\right)^{\frac{1}{\alpha_{b}-\alpha_{g}}} \Lambda_{b}, k_{b, t+1}^{S}=\left(\frac{p_{g, t+1}^{W} A_{g}^{S}}{A_{b}^{S}}\right)^{\frac{1}{\alpha_{b}-\alpha_{g}}} \Lambda_{b}
$$

and

$$
K_{t+1}^{N}=\frac{\beta}{1+\beta}\left(1-\alpha_{b}\right) A_{b}^{N}\left(\frac{p_{g, t}^{W} A_{g}^{N}}{A_{b}^{N}}\right)^{\frac{\alpha_{b}}{\alpha_{b}-\alpha_{g}}} \Lambda_{b}^{\alpha_{b}}, K_{t+1}^{S}=\frac{\beta}{1+\beta}\left(1-\alpha_{b}\right) A_{b}^{S} \Psi\left(G_{t}\right)\left(\frac{p_{g, t}^{W} A_{g}^{S}}{A_{b}^{S}}\right)^{\frac{\alpha_{b}}{\alpha_{b}-\alpha_{g}}} \Lambda_{b}^{\alpha_{b}} .
$$

Combining these equations with (10), we obtain

$$
\begin{gathered}
L_{b, t+1}^{N}=\frac{\left(1-\alpha_{b}\right)}{\left(\alpha_{b}-\alpha_{g}\right)}\left[-\alpha_{g}+\frac{\alpha_{b} \beta}{1+\beta}\left(1-\alpha_{g}\right) A_{b}^{N}\left(\frac{A_{b}^{N}}{A_{g}^{N}}\right)^{\frac{1-\alpha_{b}}{\alpha_{b}-\alpha_{g}}}\left(\frac{\left(p_{g, t}^{W}\right)^{\alpha_{b}}}{p_{g, t+1}^{W}}\right)^{\frac{1}{\alpha_{b}-\alpha_{g}}} \Lambda_{b}^{\alpha_{b}-1}\right] \\
L_{b, t+1}^{S}=\frac{\left(1-\alpha_{b}\right)}{\left(\alpha_{b}-\alpha_{g}\right)}\left[-\alpha_{g}+\frac{\alpha_{b} \beta}{1+\beta}\left(1-\alpha_{g}\right) A_{b}^{S}\left(\frac{A_{b}^{S}}{A_{g}^{S}}\right)^{\frac{1-\alpha_{b}}{\alpha_{b}-\alpha_{g}}}\left(\frac{\left(p_{g, t}^{W}\right)^{\alpha_{b}}}{p_{g, t+1}^{W}}\right)^{\frac{1}{\alpha_{b}-\alpha_{g}}} \Lambda_{b}^{\alpha_{b}-1} \Psi\left(G_{t}\right)\right]
\end{gathered}
$$


The key variable that guarantees world general equilibrium with international trade is the world relative price $p_{g, t}^{W}$. Equation (28) can be written as

$$
\begin{aligned}
& -\frac{(1+\beta) \alpha_{g}}{\beta \alpha_{b}\left(1-\alpha_{g}\right)}+A_{b}^{N}\left(\frac{A_{b}^{N}}{A_{g}^{N}}\right)^{\frac{1-\alpha_{b}}{\alpha_{b}-\alpha_{g}}}\left(\frac{\left(p_{g, t}^{W}\right)^{\alpha_{b}}}{p_{g, t+1}^{W}}\right)^{\frac{1}{\alpha_{b}-\alpha_{g}}} \Lambda_{b}^{\alpha_{b}-1} \\
& +\left(\frac{A_{b}^{N}}{A_{b}^{S}}\right)^{\frac{\alpha_{g}}{\alpha_{b}-\alpha_{g}}}\left(\frac{A_{g}^{S}}{A_{g}^{N}}\right)^{\frac{\alpha_{b}}{\alpha_{b}-\alpha_{g}}} \Psi\left(G_{t}\right)\left(-\frac{(1+\beta) \alpha_{g}}{\beta \alpha_{b}\left(1-\alpha_{g}\right)}+A_{b}^{S}\left(\frac{A_{b}^{S}}{A_{g}^{S}}\right)^{\frac{1-\alpha_{b}}{\alpha_{b}-\alpha_{g}}}\left(\frac{\left(p_{g, t}^{W}\right)_{b}}{p_{g, t+1}^{W}}\right)^{\frac{1}{\alpha_{b}-\alpha_{g}}} \Psi\left(G_{t}\right) \Lambda_{b}^{\alpha_{b}-1}\right) \\
& =\frac{\left(\alpha_{b}-\alpha_{g}\right)}{\alpha_{b}\left(1-\alpha_{g}\right)}\left(1+\left(\frac{A_{b}^{N}}{A_{b}^{S}}\right)^{\frac{\alpha_{g}}{\alpha_{b}-\alpha_{g}}}\left(\frac{A_{g}^{S}}{A_{g}^{N}}\right)^{\frac{\alpha_{b}}{\alpha_{b}-\alpha_{g}}} \Psi\left(G_{t}\right)\right)
\end{aligned}
$$

and after simplifications

$$
\begin{aligned}
& A_{b}^{N}\left(\frac{A_{b}^{N}}{A_{g}^{N}}\right)^{\frac{1-\alpha_{b}}{\alpha_{b}-\alpha_{g}}}\left(\frac{\left(p_{g, t}^{W}\right)^{\alpha_{b}}}{p_{g, t+1}^{W}}\right)^{\frac{1}{\alpha_{b}-\alpha_{g}}} \Lambda_{b}^{\alpha_{b}-1}\left(1+\left(\frac{A_{b}^{S}}{A_{b}^{N}}\right)^{\frac{1-2 \alpha_{g}}{\alpha_{b}-\alpha_{g}}}\left(\frac{A_{g}^{N}}{A_{g}^{S}}\right)^{\frac{1-2 \alpha_{b}}{\alpha_{b}-\alpha_{g}}} \Psi\left(G_{t}\right)^{2}\right) \\
& =\frac{\beta \alpha_{b}+\alpha_{g}}{\beta \alpha_{b}\left(1-\alpha_{g}\right)}\left(1+\left(\frac{A_{b}^{N}}{A_{b}^{S}}\right)^{\frac{\alpha_{g}}{\alpha_{b}-\alpha_{g}}}\left(\frac{A_{g}^{S}}{A_{g}^{N}}\right)^{\frac{\alpha_{b}}{\alpha_{b}-\alpha_{g}}} \Psi\left(G_{t}\right)\right)
\end{aligned}
$$

Lemma follows.

\subsection{Existence and unicity of steady state: Proof of Proposition 1}

Combining equations (19) and (20) provided in Lemma 2, a steady state equilibrium $\bar{G}$ has to satisfy

$$
\left\{\begin{array}{l}
\mathcal{F}_{1}(\bar{G})=\mathcal{F}_{2}(\bar{G}) \\
\bar{G}<\Omega
\end{array}\right.
$$

with

$$
\begin{aligned}
& \mathcal{F}_{1}(G) \equiv(G)^{\frac{\alpha_{b}-\alpha_{g}}{\alpha_{b}}}\left(\frac{\theta}{\eta} \frac{\left(1-\alpha_{b}\right)}{\left(\alpha_{b}-\alpha_{g}\right)}\left(A_{b}^{N}\right)^{\frac{1}{1-\alpha_{b}}}\right)^{\frac{-\alpha_{b}+\alpha_{g}}{\alpha_{b}}} \times \\
& \left(\frac{\left(\beta \alpha_{b}+\alpha_{g}\right) \Upsilon(G)}{(1+\beta)}\left[1+\Psi(G)\left(\frac{B}{T}\right)^{\frac{1}{\alpha_{b}-\alpha_{g}}}\right]-\alpha_{g}\left[1+\left(\frac{B^{\alpha_{g}}}{T^{\alpha_{b}}}\right)^{\frac{1}{\alpha_{b}-\alpha_{g}}}\right]\right)^{\frac{-\alpha_{b}+\alpha_{g}}{\alpha_{b}}}
\end{aligned}
$$

and

$$
\mathcal{F}_{2}(G) \equiv\left(\frac{\beta \alpha_{b}+\alpha_{g}}{\beta \alpha_{b}\left(1-\alpha_{g}\right)} \Upsilon(G)\right)^{\frac{\alpha_{b}}{\alpha_{b}-1}}
$$

The corresponding steady state relative price is given by:

$$
\bar{p}_{g}^{W}=\mathcal{F}_{1}(\bar{G})
$$


The threshold $\Omega$ is given by $\Omega=\min \left\{G_{1}, G_{2}\right\}$ with $G_{1}$ and $G_{2}$ such that $L_{b}^{S}\left(T, G_{1}\right)=0$ and $L_{b}^{N}\left(T, G_{2}\right)=1$. The condition $G<\Omega$ thus guarantees that the equilibrium steady state is diversified, i.e. $0<L_{b}^{N}, L_{b}^{S}<1$. Under Assumptions 1-3, the function $\mathcal{F}_{1}(G)$ is positive and it is increasing and then decreasing in $G$ with $\partial \mathcal{F}_{1}(\Omega) / \partial G>0 . \mathcal{F}_{1}(G)$ is thus increasing in $(0, \Omega)$ with $\mathcal{F}_{1}(0)=0$. The sign of the slope of function $\mathcal{F}_{2}(G)$ is driven by:

$$
\Upsilon(G)^{-1}=\frac{1+(\Psi(G))^{2}\left(\frac{1}{B}\right)^{\frac{1-2 \alpha_{g}}{\alpha_{b}-\alpha_{g}}}(T)^{\frac{1-2 \alpha_{b}}{\alpha_{b}-\alpha_{g}}}}{1+\Psi(G)\left(\frac{B^{\alpha_{g}}}{T^{\alpha_{b}}}\right)^{\frac{1}{\alpha_{b}-\alpha_{g}}}}
$$

Under Assumptions 1-3, this term is decreasing in $G$ when $G<\Omega$. Thus, for $G<\Omega, \mathcal{F}_{2}(G)$ is downward sloping with $\mathcal{F}_{2}(0)>0$ and $\mathcal{F}_{2}(\Omega)>0$ and $\mathcal{F}_{1}(G)$ is upward sloping with $\mathcal{F}_{1}(0)=0$ and $\mathcal{F}_{1}(\Omega)>0$. The condition to have a long-term diversified equilibrium is thus that:

$$
\mathcal{F}_{1}(\Omega)>\mathcal{F}_{2}(\Omega)
$$

From (4), (17) and (18), an increase in $\gamma$ causes $\Omega$ to fall and hence causes $\mathcal{F}_{1}(\Omega)$ to fall and $\mathcal{F}_{2}(\Omega)$ to rise. When $\gamma=0, \Omega$ tends to infinity with $\lim _{\Omega \rightarrow \infty} \mathcal{F}_{1}(\Omega)>\lim _{\Omega \rightarrow \infty} \mathcal{F}_{2}(\Omega)$. When $\gamma$ tends to infinity, $\Omega$ is equal to zero with $\mathcal{F}_{1}(0)<\mathcal{F}_{2}(0)$. As a result, there exists a threshold $\bar{\gamma}$ such that when $\gamma<\bar{\gamma}$ the condition given by (29) holds. In this case, there exists a unique steady state: $\bar{G} \equiv \bar{G}(\gamma) \in(0, \Omega)$.

\subsection{Welfare Analysis: Short-term implications in the non-vulnerable economy}

The indirect utility in the North is given by the following expression:

$$
V^{N}\left(w_{t}^{N}, R_{t+1}^{N}, p_{g, t}^{W}, p_{g, t+1}^{W}\right)=\ln \left(\frac{1}{1+\beta} \frac{w_{t}^{N}}{p_{g, t}^{W}}\right)+\beta \ln \left(\frac{\beta}{1+\beta} \frac{R_{t+1}^{N}}{p_{t+1}^{W}} w_{t}^{N}\right)
$$

We can express factor prices as functions of the relative price by using (9). In this way, we obtain a function that depends on the relative price only:

$$
V^{N}\left(p_{g, t}^{W}, p_{g, t+1}^{W}\right)=\mathcal{C}_{1}+\left(\frac{\alpha_{g}+\alpha_{b} \beta}{\alpha_{b}-\alpha_{g}}\right) \ln \left(p_{g, t}^{W}\right)-\beta\left(\frac{1-\alpha_{g}}{\alpha_{b}-\alpha_{g}}\right) \ln \left(p_{g, t+1}^{W}\right)
$$


with

$\mathcal{C}_{1}=\ln \left(\frac{1}{1+\beta}\right)+\beta \ln \left(\frac{\beta}{1+\beta}\right)+(1+\beta) \ln \left[\left(1-\alpha_{b}\right) A_{b}\left(\frac{A_{g}}{A_{b}}\right)^{\frac{\alpha_{b}}{\alpha_{b}-\alpha_{g}}} \Lambda_{b}^{\alpha_{b}}\right]+\beta \ln \left[\left(1-\alpha_{b}\right) A_{b}\left(\frac{A_{g}}{A_{b}}\right)^{\frac{\alpha_{b}-1}{\alpha_{b}-\alpha_{g}}} \Lambda_{b}^{\alpha_{b}-1}\right]$

As $p_{g, t+1}^{W}$ is a function of $p_{g, t}^{W}$ and $G_{t}$, using equation (15), we can also express the indirect utility as:

$$
V^{N}\left(p_{g, t}^{W}, G_{t}\right)=\mathcal{C}_{2}+\left(\alpha_{g} \frac{1+\alpha_{b} \beta}{\alpha_{b}-\alpha_{g}}\right) \ln \left(p_{g, t}^{W}\right)+\beta\left(1-\alpha_{g}\right) \ln \left(\Upsilon\left(G_{t}\right)\right)
$$

with

$$
\mathcal{C}_{2}=\mathcal{C}_{1}-\beta\left(1-\alpha_{b}\right) \ln \left(\frac{\beta \alpha_{b}\left(1-\alpha_{g}\right)}{\beta \alpha_{b}+\alpha_{g}}\right)
$$

To describe the dynamics of this model, we define the two loci GG $\equiv\left\{\left(p_{g, t}^{W}, G_{t}\right): G_{t+1}=G_{t}=G\right\}$ and $\mathrm{PP} \equiv\left\{\left(p_{g, t}^{W}, G_{t}\right): p_{g, t+1}^{W}=p_{g, t}^{W}=p_{g}^{W}\right\}$. Using Lemma 1, we have:

$$
\begin{aligned}
& \text { GG locus : } p_{g}^{W}=(G)^{\frac{\alpha_{b}-\alpha_{g}}{\alpha_{b}}}\left(\frac{\theta}{\eta} \frac{\left(1-\alpha_{b}\right)}{\left(\alpha_{b}-\alpha_{g}\right)}\left(A_{b}^{N}\right)^{\frac{1}{1-\alpha_{b}}}\right)^{\frac{-\alpha_{b}+\alpha_{g}}{\alpha_{b}}} \times \\
& \left(\frac{\left(\beta \alpha_{b}+\alpha_{g}\right) \Upsilon(G)}{(1+\beta)}\left[1+\Psi(G)\left(\frac{B}{T}\right)^{\frac{1}{\alpha_{b}-\alpha_{g}}}\right]-\alpha_{g}\left[1+\left(\frac{B^{\alpha_{g}}}{T^{\alpha_{b}}}\right)^{\frac{1}{\alpha_{b}-\alpha_{g}}}\right]\right)^{\frac{-\alpha_{b}+\alpha_{g}}{\alpha_{b}}}=\mathcal{F}_{1}(G) \\
& \text { PP locus : } p_{g}^{W}=\left(\frac{\beta \alpha_{b}+\alpha_{g}}{\beta \alpha_{b}\left(1-\alpha_{g}\right)} \Upsilon(G)\right)^{\frac{\alpha_{b}}{\alpha_{b}-1}}=\mathcal{F}_{2}(G)
\end{aligned}
$$

The functions $\mathcal{F}_{1}(G)$ and $\mathcal{F}_{2}(G)$ are already defined in Appendix 6.2, to derive the existence of the steady state. The dynamics in the North economy can be depicted by a phase diagram whose phase lines are given by GG and PP loci. Under Assumptions 1-3, the term $\Upsilon(G)$ is increasing in $G$ for $G \in(0, \Omega)$ meaning that PP locus is downward sloping. Using the results provided in Appendix 6.2, GG locus is upward sloping for $G \in(0, \Omega)$. Thus, the dynamics can be depicted in Figure 2.

The transitional path depends on initial conditions on the pollution stock $G_{t=0} \equiv G_{0}$ and on the price $p_{g, t=0}^{W} \equiv p_{g, 0}^{W}$. The latter is given by initial conditions on the capital stocks of North and South $K_{0}^{N}$ and $K_{0}^{S}$, and on pollution $G_{0}$. Indeed, from (8) and (10), we have $L_{b, t}^{i} \equiv L_{b}^{i}\left(K_{t}^{i}, p_{g, t}^{W}\right)$. Replacing it in the equilibrium condition on the brown good market (14) and using (6), we have:

$$
A_{b}^{N} L_{b}^{N}\left(K_{t}^{N}, p_{g, t}^{W}\right)+A_{b}^{S} L_{b}^{S}\left(K_{t}^{S}, p_{g, t}^{W}\right) \Psi\left(G_{t}\right)=\frac{\left(1-\alpha_{b}\right) \beta}{1+\beta}\left(A_{b}^{N}+\Psi\left(G_{t}\right) A_{b}^{S}\right)
$$


From this equality, we have:

$$
p_{g, 0}^{W}=\underset{+}{\Theta\left(K_{0}^{N}, K_{0}^{S}, G_{0}\right)}
$$

with $\Theta\left(0, K_{0}^{S}, G_{0}\right)>0, \Theta\left(K_{0}^{N}, 0, G_{0}\right)>0, \Theta\left(0,0, G_{0}\right)=0$ and $\Theta\left(K_{0}^{N}, K_{0}^{S}, 0\right)>0$. We focus on the case in which $G_{0}<\bar{G}$, and $p_{g, 0}^{W}<p^{\max }$ with $p^{\max }$ the relative price of good in the absence of

pollution. In that case, we can observe a transitional path with a decreasing trend in $p_{g}^{W}$ if initial conditions on $K^{S}, K^{N}$ and $G$ are such that the initial relative price $p_{g, 0}^{W}$ is above the PP locus that prevails along the steady state. Finally, we can summarize this situation by the following conditions:

$$
\left(\frac{\beta \alpha_{b}+\alpha_{g}}{\beta \alpha_{b}\left(1-\alpha_{g}\right)} \Upsilon(\bar{G})\right)^{\frac{\alpha_{b}}{\alpha_{b}-1}} \equiv \bar{p}_{g}^{W}<\Theta\left(K_{0}^{N}, K_{0}^{S}, G_{0}\right)<\left(\frac{\beta \alpha_{b}+\alpha_{g}}{\beta \alpha_{b}\left(1-\alpha_{g}\right)} \Upsilon\left(G_{0}\right)\right)^{\frac{\alpha_{b}}{\alpha_{b}-1}} \equiv p^{\max }
$$

and

$$
G_{0}<\bar{G}
$$

In the absence of damage, $\gamma=0$, we have $\bar{p}_{g}^{W}=p^{\max }$, meaning that the condition (31) never holds. Under Assumptions 1-3 and $\gamma<\bar{\gamma}, \Upsilon(G)$ is increasing in $G$. For all initial values $G_{0}<\bar{G}$, we thus have $\bar{p}_{g}^{W}<p^{\max }$. Given the properties of the function $\Theta\left(K_{0}^{N}, K_{0}^{S}, G_{0}\right)$ presented above, when $G_{0}<\bar{G}$ there always exists a set of value $\left(K_{0}^{N}, K_{0}^{S}\right)$ that satisfies inequality (31) and hence the condition (31) to observe a decreasing trend in $p_{g}^{W}$ over time.

\subsection{Welfare Analysis: Long-term implications in the non-vulnerable economy}

The stationnary indirect utility in the North is given by the following expression:

$$
V\left(w^{N}, R^{N}, p_{g}^{W}\right)=\ln \left(\frac{1}{1+\beta} \frac{w^{N}}{p_{g}^{W}}\right)+\beta \ln \left(\frac{\beta}{1+\beta} \frac{R^{N}}{p^{W}} w^{N}\right) \equiv V^{N}
$$

Let $\omega^{N}=w^{N} / p_{g}^{W}$, from (32) it follows that:

$$
\operatorname{sgn} \mathrm{d} V^{N}=\left[\frac{\mathrm{d} \omega^{N}}{\mathrm{~d} p_{g}^{W}}+\frac{\beta}{1+\beta} \frac{\omega^{N}}{R^{N}} \frac{\mathrm{d} R^{N}}{\mathrm{~d} p_{g}^{W}}\right] \mathrm{d} p_{g}^{W}
$$

Using the fact that

$$
\mathrm{d} \omega^{N} / \mathrm{d} p_{g}^{W}=\left(p_{g}^{W}\right)^{-1}\left(\mathrm{~d} w^{N} / \mathrm{d} p_{g}^{W}-w^{N} / p_{g}^{W}\right)
$$


and

$$
\frac{\beta}{1+\beta} w^{N}=K^{N}
$$

we have:

$$
\operatorname{sgn} \mathrm{d} V^{N}=\left[\frac{K^{N}}{R^{N}} \frac{\mathrm{d} R^{N}}{\mathrm{~d} p_{g}^{W}}-\frac{w^{N}}{p_{g}^{W}}+\frac{\mathrm{d} w^{N}}{\mathrm{~d} p_{g}^{W}}\right] \mathrm{d} p_{g}^{W}
$$

In each country, the gross domestic product is equal to the total revenue of capital and workers:

$$
\left[Y_{b}^{N}+Y_{g}^{N} p_{g}^{W}\right]=w^{N}+R^{N} K^{N}
$$

By differentiating this equation, we obtain:

$$
\begin{gathered}
Y_{g}^{N} \mathrm{~d} p_{g}^{W}=\mathrm{d} w^{N}+K^{N} \mathrm{~d} R^{N} \\
\frac{\mathrm{d} w^{N}}{\mathrm{~d} p_{g}^{W}}=Y_{g}^{N}-\frac{K^{N} \mathrm{~d} R^{N}}{\mathrm{~d} p_{g}^{W}}
\end{gathered}
$$

Combining (34) and (35), we obtain:

$$
\frac{\mathrm{d} w^{N}}{\mathrm{~d} p_{g}^{W}}=\frac{w^{N}+R^{N} K^{N}-Y_{b}^{N}}{p_{g}^{N}}-\frac{K^{N} \mathrm{~d} R^{N}}{\mathrm{~d} p_{g}^{W}}
$$

Moreover differentiating factor price, we have:

$$
\frac{\mathrm{d} w^{N}}{\mathrm{~d} p_{g}^{W}}=\frac{\alpha_{b}}{\alpha_{b}-\alpha_{g}} \frac{w^{N}}{p_{g}^{W}} ; \frac{\mathrm{d} R^{N}}{\mathrm{~d} p_{g}^{W}}=-\frac{1-\alpha_{b}}{\alpha_{b}-\alpha_{g}} \frac{R^{N}}{p_{g}^{W}}
$$

Using (36) and (37), equation (33) can be written as:

$$
\operatorname{sgn}\left(\frac{d V^{N}}{\mathrm{~d} p_{g}^{W}}\right)=\frac{K^{N}}{R^{N}} \frac{\mathrm{d} R^{N}}{\mathrm{~d} p_{g}^{W}}-\frac{w^{N}}{p_{g}^{W}}+\frac{w^{N}+R^{N} K^{N}-Y_{b}^{N}}{p_{g}^{N}}-\frac{K^{N} \mathrm{~d} R^{N}}{\mathrm{~d} p_{g}^{W}}
$$

and after simplifications, we have:

$$
\operatorname{sgn}\left(\frac{d V}{\mathrm{~d} p_{g}^{W}}\right)=\frac{K^{N}}{R^{N}} \frac{\mathrm{d} R^{N}}{\mathrm{~d} p_{g}^{W}}\left(1-R^{N}\right)+\frac{R^{N} K^{N}-Y_{b}^{N}}{p_{g}^{N}}
$$

Using (37),

$$
\operatorname{sgn}\left(\frac{d V^{N}}{\mathrm{~d} p_{g}^{W}}\right)=\left(\frac{-\left(1-\alpha_{b}\right)\left(1-R^{N}\right) K^{N}}{\alpha_{b}-\alpha_{g}}+R^{N} K^{N}-Y_{b}^{N}\right) \times \frac{1}{p_{g}^{W}}
$$


Finally, this expression can be expressed as follows:

$$
\operatorname{sgn}\left(\frac{d V^{N}}{\mathrm{~d} p_{g}^{W}}\right)=\left(\frac{\left(1-\alpha_{g}\right) R^{N} K^{N}-K^{N}\left(1-\alpha_{g}\right)+K^{N}\left(\alpha_{b}-\alpha_{g}\right)}{\alpha_{b}-\alpha_{g}}-Y_{b}^{N}\right) \times \frac{1}{p_{g}^{W}}
$$

and we obtain the indirect utility given by equation (25).

\subsection{Pattern of trade along the steady state: Proof of Propositions 3 and 4}

Using (26), the pattern of specialization along the steady state is the following:

a) When $\Psi(\gamma)>\frac{(B)^{\frac{1-\alpha_{g}}{\alpha_{b}-\alpha_{g}}}}{(T)^{\frac{1-\alpha_{b}}{\alpha_{b}-\alpha_{g}}}}$ North is a net exporter of the green good.

b) When $\Psi(\gamma)<\frac{(B)^{\frac{1-\alpha_{g}}{\alpha_{b}-\alpha_{g}}}}{(T)^{\frac{1-\alpha_{b}}{\alpha_{b}-\alpha_{g}}}}$ North is a net exporter of the brown good.

It depends on how the undamaged part of production $\Psi(\gamma)$ responds to the South's vulnerability $\gamma$. For $\gamma=0, \Psi(\gamma)=1$ and the scenario $a$ is observed. For $\gamma=\bar{\gamma}$, under Assumption 3, North is perfectly specialized in the brown good and the scenario $b$ is observed.

From (4), we have:

$$
\frac{\partial \Psi(\gamma)}{\partial \gamma}=-(G(\gamma))^{2} \frac{\Psi(\gamma)}{1+\gamma(G(\gamma))^{2}}\left(\varepsilon_{G / \gamma}+\frac{1}{2}\right)
$$

with $\varepsilon_{G / \gamma}=\frac{\partial G(\gamma)}{\partial \gamma} \frac{\gamma}{G(\gamma)}$. Thus, when $\left|\varepsilon_{G / \gamma}\right|<1 / 2$, we have $\frac{\partial \Psi(\gamma)}{\partial \gamma}<0$ and there exists a threshold $\hat{\gamma}(\beta) \in(0, \bar{\gamma})$ such that $\Psi(\hat{\gamma}(\beta))=\frac{(B)^{\frac{1-\alpha_{g}}{\alpha_{b}-\alpha_{g}}}}{(T)^{\frac{1-\alpha_{b}}{\alpha_{b}-\alpha_{g}}}}$.

The way the damages from climate change affect the North along the steady state depends largely on capital accumulation, which is driven by agent's time preference $\beta$. We have thus defined the steady state value for pollution as $\bar{G} \equiv G(\gamma, \beta)$ and the threshold on $\gamma$ as a function of $\beta$. We have $\frac{\partial G(\gamma, \beta)}{\partial \beta}>0$. This result is derived by using functions $\mathcal{F}_{1}$ and $\mathcal{F}_{2}$, provided in Appendix 6.2, whose intersection gives the steady state equilibrium $G(\gamma, \beta)$. Following an increase in $\beta, \mathcal{F}_{1}(G)$ shifts downward while $\mathcal{F}_{2}(G)$ shifts upward, meaning that the equilibrium value $G(\gamma, \beta)$ increases. As $G(\gamma, \beta)$ is an increasing function of $\beta$, from $(26), \hat{\gamma}(\beta)$ goes down with $\beta$. Then, the propositions follow. 


\subsection{Proof of Proposition 5}

The social welfare in the North, defined by a social planner that treats all northern generations equally, is maximized for an allocation that satisfies that the marginal product of capital is equal to one (i.e. $R^{N}=1$ ). Using (6) along the steady state, we obtain that a marginal product of

capital equal to one implies $k_{b}^{N}=\left(A_{b}^{N} \alpha_{b}\right)^{\frac{1}{1-\alpha_{b}}}$. From the equilibrium on the brown good market along the steady state, $K^{N}=Y_{b}^{N}$, and (1), we have:

$$
K^{N}=\frac{A_{b}^{N}\left(k_{b}^{N}\right)^{\alpha_{b}}\left(1-\alpha_{b}\right)}{A_{b}^{N}\left(1-\alpha_{g}\right) \alpha_{b}\left(k_{b}^{N}\right)^{\alpha_{b}-1}+\alpha_{g}-\alpha_{b}}
$$

The stock of capital that guarantees a steady state marginal product of capital equal to one in the North is thus:

$$
K^{N}=A_{b}^{N}\left(A_{b}^{N} \alpha_{b}\right)^{\frac{\alpha_{b}}{1-\alpha_{b}}} \equiv \tilde{K}^{N}
$$

From (8), (13), (20) and the equilibrium on the capital market along the steady state, $K^{N}=s^{N}$, the stationary competitive stock of capital is:

$$
K^{N}=\frac{\beta}{1+\beta}\left(1-\alpha_{b}\right)\left(A_{b}^{N}\right)^{\frac{1}{1-\alpha_{b}}}\left(\frac{\beta \alpha_{b}\left(1-\alpha_{g}\right)}{\left(\beta \alpha_{b}+\alpha_{g}\right) \Upsilon(G(\gamma, \beta))}\right)^{\frac{\alpha_{b}}{1-\alpha_{b}}} \equiv K^{N}(\gamma, \beta)
$$

Under Assumptions 1-3 and for $\gamma<\bar{\gamma}$ and $\left|\varepsilon_{G / \gamma}\right|<1 / 2, \Upsilon(G(\gamma, \beta))$ increases with $\gamma$ which implies $\partial K^{N} / \partial \gamma<0$. Indeed, $\Upsilon$ depends on $\gamma$ only through the undamaged part of production $\Psi$. From Assumptions 1-3 and for $\gamma<\bar{\gamma}$, the term $\Upsilon$ goes down with $\Psi$ and for $\left|\varepsilon_{G / \gamma}\right|<1 / 2$ the undamaged part of production falls with $\gamma$ along the steady state.

The competitive stock of capital corresponds to those maximizing the social welfare in the North if and only if:

$$
K^{N}(\gamma, \beta)=\tilde{K}^{N} \Leftrightarrow \frac{\beta}{1+\beta}\left(1-\alpha_{b}\right)\left(\frac{\beta\left(1-\alpha_{g}\right)}{\left(\beta \alpha_{b}+\alpha_{g}\right) \Upsilon(G(\gamma, \beta))}\right)^{\frac{\alpha_{b}}{1-\alpha_{b}}}=1
$$

Under Assumptions 1-3 and for $\gamma<\bar{\gamma}$, there exists a unique value of $\gamma, \tilde{\gamma}(\beta)$, which guarantees that the competitive stock of capital satisfied $R^{N}=1$. When $\gamma>\tilde{\gamma}(\beta), R^{N}>1$ and $K^{N}<\tilde{K}^{N}$ : There is under-accumulation of capital. Reversely when $\gamma<\tilde{\gamma}(\beta), R^{N}<1$ and $K^{N}>\tilde{K}^{N}$ : There is over-accumulation of capital. Under Assumptions 1-3 and for $\gamma<\bar{\gamma}$, we have the following properties for $\tilde{\gamma}(\beta)$ : $\tilde{\gamma}(\beta)$ decreases with $\beta$ and $\tilde{\gamma}(0)<0$, meaning that there is under- 
accumulation of capital $\forall \gamma$ when $\beta=0$. Given the fact that $K^{N}$ is decreasing with $\gamma$, an increase in South's vulnerability makes the competitive solution farther to the efficient allocation in the first case and closer in the second case.

\subsection{Discussion: Welfare implications of a decrease in damages on northern generations}

We do not formalize policy measures in our study but we can appreciate their potential benefits by examining the impacts of a variation in parameters $\theta$ and/or $\gamma$. We can suppose an investment in clean development mechanisms (CDM) that aims at mitigating emissions abroad (i.e. decreasing the pollution intensity $\theta$ ), or a contribution to climate funds supporting adaptation that consists in reducing the South's vulnerability (i.e. $\gamma$ ).

Leaving aside the financial cost of such an environmental policy, we provide some insight into the necessary conditions for its acceptability by the different generations alive when the policy is first implemented in the North. To this aim, we examine the distributive effect of an exogenous fall in damages (captured by a decrease in $\gamma$ and/or $\theta$ ) between consumption of young and old people at the steady state. ${ }^{18}$

The following expressions correspond to the welfare - indirect utility - of the young $\left(V^{N y}\left(p_{g}^{W}\right)\right)$ and of the old $\left(V^{N o}\left(p_{g}^{W}\right)\right)$ northern agents that coexist along the steady state:

$$
V^{N y}\left(p_{g}^{W}\right)=\mathcal{C}^{y}+\frac{\alpha_{g}}{\alpha_{b}-\alpha_{g}} \ln \left(p_{g}^{W}\right) ; V^{N o}\left(p_{g}^{W}\right)=\mathcal{C}^{o}+\frac{\alpha_{b}+\alpha_{g}-1}{\alpha_{b}-\alpha_{g}} \ln \left(p_{g}^{W}\right)
$$

with $\mathcal{C}^{y}=\ln \left(A_{b}^{N}\left(1-\alpha_{b}\right) \Lambda_{b}^{\alpha_{b}}\left[\frac{A_{g}^{N}}{A_{b}^{N}}\right]^{\frac{\alpha_{b}}{\alpha_{b}-\alpha_{g}}}\right)$ and $\mathcal{C}^{o}=\ln \left(\left(A_{b}^{N}\right)^{2} \alpha_{b}\left(1-\alpha_{b}\right) \Lambda_{b}^{2 \alpha_{b}-1}\left[\frac{A_{g}^{N}}{A_{b}^{N}}\right]^{\frac{2 \alpha_{b}-1}{\alpha_{b}-\alpha_{g}}}\right)$.

From the previous analysis, we know that an -exogenous- decrease in damages in the long run increases the relative price $p_{g}^{W}$ (see Lemma 1 with Assumptions 1 to 3 ). Using the indirect utility functions given in (39), we obtain:

Result 1. Under Assumptions 1-3, let $\left|\varepsilon_{G / \gamma}\right|<1 / 2$ and $\gamma<\bar{\gamma}$. At the steady state, when the damages from climate change on the South decrease, the welfare of the northern young always increases while the welfare of the northern elderly decreases (resp. increases) for $\alpha_{b}+\alpha_{g}<1$ (resp. $\left.\alpha_{b}+\alpha_{g}>1\right)$.

\footnotetext{
${ }^{18} \mathrm{~A}$ fall in $\theta$ reduces the damage by its negative impact on the long run stock of pollution. A fall in $\gamma$ reduces the damage in the long run provided that the elasticity of long run pollution stock to $\gamma$ is not too high.
} 
This result gives intuitions about how northern agents coexisting at a given period of time are affected by a reduction in environmental damages in the South. We reveal that it could create a potential conflict between the two generations - young and old - as they are not affected in the same way by the spillover effects of pollution.

As the damages in the South lower the return of labor, it necessarily decreases the first period utility of young northern agents. However, in the absence of direct damages from climate change in the North, the elderly benefits from the damages in the South when capital intensity is not too high $\left(\alpha_{b}+\alpha_{g}<1\right)$. Under this condition, they have no economic incentive to accept and to contribute to the funding of an environmental policy aiming at proving assistance to the South. Even if such measures may generate benefits in the future, these benefits would occur beyond the lifespan of the elderly generation.

\section{References}

Andersen, D.C. (2017) "Do credit constraints favor dirty production? Theory and plant-level evidence", Journal of Environmental Economics and Management 84, 189-208.

Ayong Le Kama, A. and Pommeret, A. (2016), "Supplementing Domestic Mitigation and Adaptation with Emissions Reduction Abroad to Face Climate Change", Environmental and Resource Economics doi:10.1007/s10640-016-0050-2.

Broner, F., Bustos, P. and Carvalho, V.M. (2012), "Sources of Comparative Advantage in Polluting Industries", National Bureau of Economic Research (No. w18337).

Burke, M., Hsiang, S.M. and Miguel, E. (2015), "Global Non-linear Effect of Temperature on Global on Economic Production", Nature 527, 235-239.

Chiroleu-Assouline, M. and Fodha,M. (2005), "Double Dividend with Involuntary Unemployment: Efficiency and Intergenerational Equity", Environmental and Resource Economics31 (4) 389403.

Cole, M.A. and Elliott, R.J.R. (2005), "FDI and the Capital Intensity of "Dirty" Sectors: A Missing Piece of the Pollution Haven Puzzle", Review of Development Economics 9(4), 530548.

Cole, M.A., Elliott, R.J.R. and Shimamoto, K. (2005), "Industrial Characteristics, Environmental Regulations and Air Pollution: An Analysis of the UK Manufacturing Sector", Journal of Environmental Economics and Management 50, 121-143.

Cole, M.A., Elliott, R.J.R. and Wu, S. (2008) "Industrial Activity and the Environment in China: An Industry-Level Analysis", China Economic Review 19, 393-408.

Constant, K. and Davin, M. (2017), "Environmental Policy and Growth when Environmental Awareness is Endogenous", Macroeconomic Dynamics forthcoming.

Copeland, B.R. and Taylor, M.S. (2004), "Trade, Growth and the Environment", Journal of Economic Literature 42, 7-71.

Costinot, A., Donaldson, D. and Smith, C. (2016), "Evolving Comparative Advantage and the Impact of Climate Change in Agricultural Markets: Evidence from 1.7 Million Fields around the World", Journal of Political Economy 124 (1), 205-248. 
Dell, M., Jones, B.F. and Olken, B.A. (2012), "Temperature Shocks and Economic Growth: Evidence from the Last Half Century", American Economic Journal: Macroeconomics 4(3), 66-95.

Dietz, S. and Stern, N. (2015), "Endogenous Growth, Convexity of Damage and Climate Risk: How Nordhaus' Framework Supports Deep Cuts in Carbon Emissions", The Economic Journal $125,574-620$.

Fadinger, H. and Fleiss, P. (2011), "Trade and Sectoral Productivity", The Economic Journal 121, 958-989.

Golosov, M., Hassler, J., Krusell, P. and Tsyvinski, A. (2014), "Optimal Taxes on Fossil Fuel in General Equilibrium", Econometrica 82(1), 41-88.

Howarth, R.B. and Norgaard, R. (1992), "Environmental Valuation under Sustainable Development", American Economic Review 82(2), 473-477.

Intergovernmental Panel on Climate Change (2014), Climate Change 2014: Impacts, Adaptation, and Vulnerability, Cambridge University Press.

John, A. and Pecchenino R. (1994), "An Overlapping Generations Model of Growth and the Environment", Economic Journal 104, 1393-1410.

Jones, B.F. and Olken, B.A. (2010), "Climate Shocks and Exports", American Economic Review: Papers 83 Proceedings 100, 454-459.

Karp, L. and Rezai, A. (2014), "The Political Economy of Environmental Policy with Overlapping Generations", International Economic Review 55(3), 711-733.

Kerr, W. R. (2017) "Heterogeneous Technology Diffusion and Ricardian Trade Patterns", World Bank Economic Review, Forthcoming.

Managi, S., Hibiki, A. and Tsurumi, T. (2009), "Does Trade Openness Improve Environmental Quality?", Journal of Environmental Economics and Management 58(3), 346-363.

Mendelsohn, R., Dinar, A. and Williams, L. (2006), "The Distributional Impact of Climate Change on Rich and Poor Countries", Environment and Development Economics 11(2), 159-178

Ollivier, H. (2016), "North-South Trade and Heterogeneous Damages from Local and Global Pollution", Environmental and Resource Economics, 65(2), p 337-355.

Oniki, H., and Uzawa, H. (1965), "Patterns of Trade and Investment in a Dynamic Model of International Trade", Review of Economic Studies 32(1), 15-37.

Schenker, O. (2013), "Exchanging Goods and Damages: The Role of Trade on the Distribution of Climate Change Costs", Environmental and Resource Economics 54, 261-282.

Schenker, O. and Stephan, G. (2014), "Give and Take: How the Funding of Adaptation to Climate Change can Improve the Donor's Terms-of-Trade", Ecological Economics 106, 44-55.

Schumacher, I. and Zou, B. (2008) "Pollution Perception: A Challenge for Intergenerational Equity", Journal of Environmental Economics and Management 55(3), 296-309.

Seegmuller, T. and Verchère, A. (2004) Pollution as a Source of Endogenous Fluctuations and Periodic Welfare Inequality in OLG Economies. Economics Letters 84, 363-369.

Stern, N. (2006), The Stern Review Report : the Economics of Climate Change, London, HMTreasury.

Varvarigos, D. (2011), "Non-Monotonic Welfare Dynamics in a Growing Economy", Journal of Macroeconomics 33(2), p 303-312. 
WTO and UNEP (2009), Trade and Climate Change - A report by the United Nations Environment Programme and the World Trade Organization. Lausanne, Switzerland.

Yenokyan, K., Seater, J.J. and Arabshahi, M. (2014), "Economic Growth with Trade in Factors of Production", International Economic Review 55(1), 223- 254. 


\section{CEE-M Working Papers1 - 2018}

WP 2018 - 01: $\quad$ Ilaria Brunetti., Mabbel Tidball, $\&$ Denis Couvet «Relationship Between Biodiversity and Agricultural Production »

WP 2018 - 02: $\quad$ Phillippe Le Coent, Raphaële Préget \& Sophie Thoyer «Do farmers follow the herd? The influence of social norms in the participation to agri-environmental schemes.»

WP 2018 - 03: $\quad$ Ludivine Roussey \& Raphael Soubeyran

« Overburdened judges »

WP 2018 - 04: $\quad$ Nicolas Quérou

« Interacting collective action problems in the

Commons »

WP 2018 - 05: $\quad$ Karine Constant \& Marion Davin

« Unequal vulnerability to climate change

and the transmission of adverse

effects through international trade» 